fi, 182

UC'RL-51361

\title{
COMPUTER PROGRAM UKO
}

\section{A. Edward Ratcliffe}

John W. White

March 29, 1973

Prepared for U.S. Atomic Energy Commission under contract No.W-7405-Eng-48
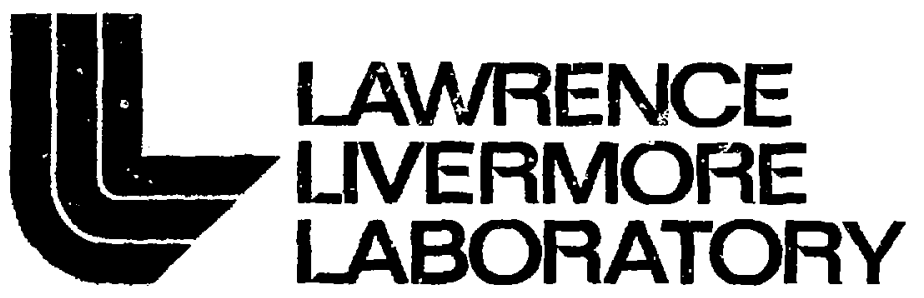

University of Calfomia/Livermore

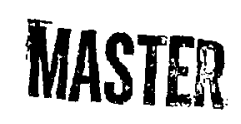

DISTRIEUTION OF THIS DOCUMENT IS UNLMITED 
NOTKE

"This report was prefared as an account of woak sponsored by the United States Govetmment. Neither the Unired States not the United States Atomle Enersy Comminsion, nor any of their employees, nor any of their coniracton, subcontrators, or theis employtes, makes any wartanty. exprest or impitied, of assumes any kel thablity or responsiblity for the aceuracy, compteleness or useluines of any informulion, apporalus, prodtuct of process dielosed, or represenis tha its use would not intringe privalely. owned riphis."

Printed in the United States of America Available from

National Technical Information Service

U.S. Department of Commerce 5285 Port Royal Road

Springfield, Virginia 22151

Price: Printed Copy \$ $\$$; Microfiche $\$ 0.95$

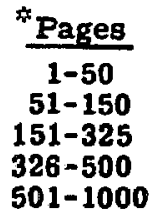

NTIS

Selling Price

$\$ 4.00$
$\$ 5.45$
$\$ 7.60$
$\$ 10.60$
$\$ 13.60$ 
TID-4500, UC-32

Mathematics and Computers

\title{
㢟 \\ LAMFENCE LNERMORE LAEOFIATORY \\ University of Caitomia/ Livemore, Caltomia/ \$4550
}

\section{UCRL-51361 \\ COMPUTER PROGRAM UKO}

\author{
A. Edward Ralcliffe
}

John W. White

March 29, 1973

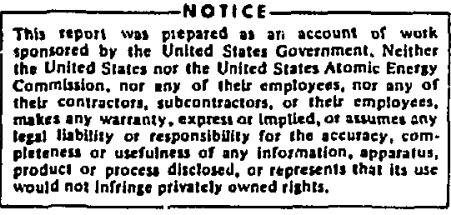




\section{Contents}

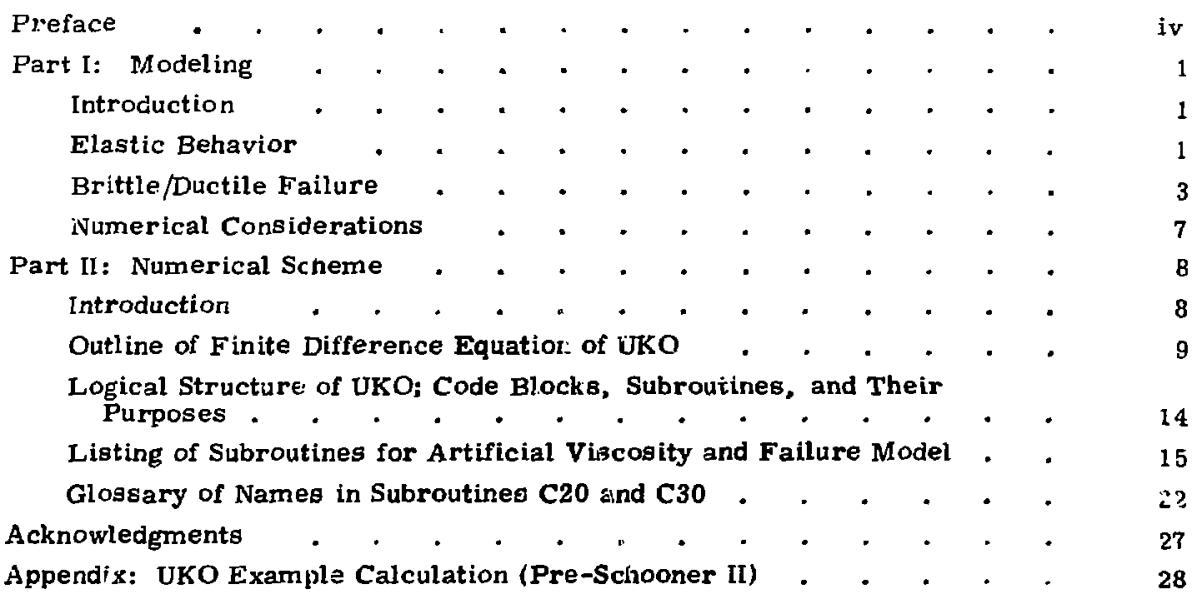




\section{Preface}

UKO is a computer program (or code) that uses the finite difference method to solve initial-value problems of continuum rock mechanics in one spatial dimension. Planar, cylindrical, and spherical symmetries are allowed. All media are assumed to be isotropic and homogeneous. The name UKO, an acronym for "Underground $\mathrm{KO}$," was chosen to indicate that the code was developed from the KO cade ${ }^{1}$ and deals with rock mechanics. KO simulates elastic behavior and plastic flow.

Rock behavior is considerably complicated by tije failure processes that occur as stress waves traverse rock media. UKO extends the KO computer program to include models to similate the brittle/ductile failure associated with rocks. Models also describe the very general failure surfaces of rock, how these surfaces change, and how str sses relax or are limited during failure. Also used in UKO is a new form of artificial viscosity tirat provides smoother and more accurate solutions.

The purpose of this report is to provide the user of UKO with a general description of the models used and to show how these models are represented in the coding. We hope that the user who reads this report and the UKO Input Description carefully will find the code to be, not a black box, but a light gray box that he can use with ease and confidence.

The user should be warned $\mathrm{L} . \quad$ sO simulates process es that are complex and subtly interrelated. Nevertheless, UK, gives the user exceptional freedom in specifying equation of state information so that a very wide range of materials and states can be represented. When improperly used, this freedom can lead to nonsensical recults. For thase reasons it is imperative that the user understand the models of the code before he uses it for quantitative predictions. No code can outguess its users, nor can it always fail safely. 


\title{
COMPUTER PROGRAM UKO
}

\author{
Part I: Modeling
}

\author{
INTRODUCTION
}

The basic equations of continuum mechanics are the conservation equations of mass, momentum, and energy; in auiution, one must have an equation-of-state (EOS) of the materials. For purely hydrodynamic (fluid) systems, the EOS can be just the expression of pressure as a function of energy (or temperature) and density. Such ase of pressure alone is limited to materials for which the stress field is always isotropic, i.e., the force per unit area at a point is the same in every direction. Solid materials cannot be characterized in this manner, because, in addition to resisting changes in density, they have the additional property of resisting changes in shape.

In this document we assume that the reader is familiar with purely hydrodynamic behavior and the use of pressure as a variable used to characterize such behavior. We also assume that the reader is familiar with the notion of approximating differential equations by finite difference equations. .n P.urt I, we present an elementary discussion of elastic behavior and numerical considerations, but we emphasize the failure description of the UKO code. We encourage the reader to read Wilkins' paper (Ref. 1).

\section{ELASTIC BEHAVIOR}

For any given infinitesimal element in an isotropic medium, it is possible to characterize the stress state by six comporents: $\sigma_{x}, \sigma_{y}, \sigma_{z}, \tau, \tau{ }^{\prime}$, and ${ }^{\top} z$. Only three of these are independent (Fig. 1).

The components $\sigma_{i}(i=x, y, z)$ represent the stress normal to the face of the element whose face is perpendicular

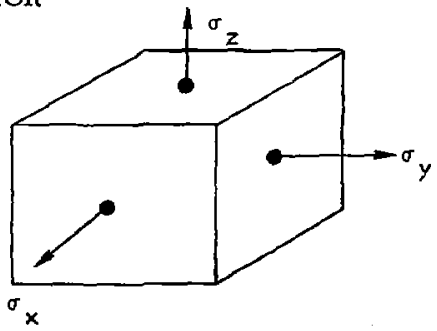

Fig. 1. Stresses normal to an infinitesimal volume.

to the 1 -axis; the shear stresses $\left(\tau_{i}\right.$, not shown in Fig. 1$)$ are stresses paraliel to the same element face. It is always possible, by rotation, to find a coordinate system for which all the $\tau^{\prime} \mathrm{s}$ are zero; this is called the princinal coordinate system. It is convenient, though not necessary, to discuss the stresses with respect to the principal coordinate system, so the stress description in the rest of this document assumes the 
principal coordinate system. Let $\sigma$ be positive for a stress directed out from the differential element. We separate the stress $\sigma_{i}$ into an isotropic component P (pressure) and a deviatoric component $\mathrm{S}_{\mathrm{i}}$.

$$
\begin{aligned}
& P=-1 / 3\left(\sigma_{1}+\sigma_{2}+\sigma_{3}\right) \\
& S_{i}=P+\sigma_{1} .
\end{aligned}
$$

Thus the pressure is just the negative of the average stress, and the ith devi 2 toric stress is just the difference between the ith principal stress and the average stress. In $\mathrm{UKO}$, changes in density a:e associated with pressure, and changes in shape are associated with the deviatoric stresses.

In Fig. 2, a shear stress $r$ is applied to an elastic solid. In elastic behavior, the solid returns to its original rectangular shape after $\tau$ is removed. We define the shear strain in this system as $\delta$, the tangent of the angle $\psi$. The material parameter of most interest in determining $\delta$ is the modulus of rigidity $G$ (also called the shear modulus), which is defined as

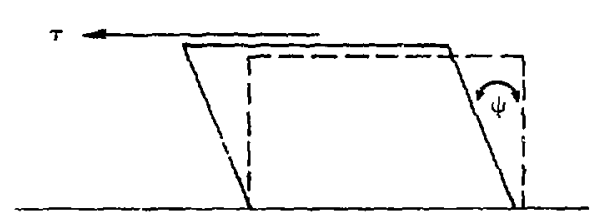

Fig. 2. Shear distortion of an infinitasimal volume. $\psi$ is an ininitesimal angle.

$$
G=\frac{T}{\delta}=\frac{\text { shear stress }}{\text { shear string }}
$$

$G$ is a measure of tixe degree to which a material can support anisotropic stresses. Thus, for hydrodynamic fluids, for which the stresses are always isotropic, $G=0$. Likewise, $G$ is also a measure of the degree to which a material resists changes in shape. In the UKO computer code, the user specifies $G$ as a function of pressure.

The material description must also include the manner in which the material resists change in density. This is required for both hydrodynamic fluids and solids. Then

$$
\frac{d V}{V}=-\frac{d P}{K}
$$

where $\mathrm{K}$ is the bulk modulus. A large value of $\mathrm{K}$ indicates that the material is hard to compress. We note also that

$$
\frac{d V}{V}=\epsilon_{1}+\epsilon_{2}+\epsilon_{3}
$$

where $\epsilon_{1}$ is the strain of elongation of the ith direction, $\langle\Delta \ell / \ell\rangle_{i}$.

In the UKO code, it proves most convenient to obtain the pressure direckly from an ECS in which the pressure is a function of density and energy. However, ihe deviatoric stresses are obtained by integrating the following equation (from Wilkins ${ }^{1}$ ):

$$
\dot{S}_{i}=2 G\left(\dot{\epsilon}_{i}-1 / 3 \dot{V} / V\right) \text {, }
$$


where the dot denotes time derivative. To this point, the behavior has been assimed to be elastic. To complete the description for rocks, failure must be included.

\section{BRITTLE/DUCTILE FAILURE}

When material fails, the stresses are relaxed \{reduce ${ }^{-1}$ in size) or their growth is limited. Before discussing this aspect of failure, we require i criterion to determine when such failure mechanisms are to occur. To discuss this citerion, we express the stress state in terms of invaricnts. There can be three iriependest invariants for any given description of a stress state. These invariants may be, of course, expressed in terms of $\sigma_{x}, \sigma_{y}, \sigma_{z}, \tau^{\prime}, \tau{ }^{\prime}$ ano' $\tau_{z}:$. Again, cur discussion is confined to the principal coordinate system for which the $\tau^{\prime}$ s are zero. One such fossible set (a standard one) of invariants follows:

$$
\begin{array}{lc}
I_{1}=\sigma_{1}+\sigma_{2}+\sigma_{3} & \text { First invariant } \\
I_{2 \mathrm{D}}=1 / 2\left(\mathrm{~S}_{1}^{2}+\mathrm{S}_{2}^{2}+\mathrm{S}_{3}^{2}\right) & \text { Second deviatoric invariant } \\
I_{3 D}=\mathrm{S}_{1} \mathrm{~S}_{2} \mathrm{~S}_{3} \cdot & \text { Third deviatoric iuvariant }
\end{array}
$$

For a more detailed discussion of invariants, the reader is referred to the books by Nadai, ${ }^{2}$ Jaeger, ${ }^{3}$ Liebowitz, ${ }^{4}$ and Jaeger and Cook. ${ }^{5}$ For convenience, in the UKO code we use the following invariants:

$$
\begin{array}{ll}
P=-1 / 3 I_{1} & \text { (pressure) } \\
\tau_{0}=\sqrt{2 / 3 I_{2 D}} & \text { (octahedral shear stress) } \\
\mathrm{I}_{3 \mathrm{D}}^{1 / 3} . &
\end{array}
$$

Note that they all have units of stress. The octahedral shear stress is the shear stress on the face of a differential element when that face is rotated so it is squally inclined to the principal axes. The expression $I_{3 D}^{1 / 3}$ is a measure of the relative values of the stresses. For example, $I_{3 D}^{1 / 3}=0$ when the greatest principal stress exceeds the average stress by the same amount that the least stress is less than the average stress. This is equivalent to saying that, for $I_{3 D}^{1 / 3}=0$, the stress state is a pure shear superimposed on a pressure. We define compression as those stress states for which

$$
\sigma_{1}<\sigma_{2}=\sigma_{3}
$$

We define extension as those stress states for which

$$
\sigma_{1}=\sigma_{2}<\sigma_{3} \text {. }
$$

[t can be shown that, for compression and extensior, 


$$
\tau_{0}= \pm \frac{2^{1 / 2}}{2^{1 / 3}} I_{3 D}^{1 / 3} .
$$

By examining a zross section of the $P, \tau_{0}, \tau_{3 D}^{1 / 3}$ space for constant $P$, we can see how the compression extension cases bound the stress space. Also, we note how a failure curve separates failed stress states from unfailed stress states (Fig. 3). (For further details regarding this strass space, see Ref. 6). Note that the failure curve in the above figure becomes a failure surface when extended in the direction of the pressure axis. Experiments on rocks are frequently reported in a curve of $\tau_{0}$ versus $P$ for several test types (i.e., compression, extension, and $I_{3 D}^{1 / 3}=0$ ), as shown in Fig. 4. The $I_{3 D}^{1 / 3}=0$ case is usually denoted by the name "torsion," since it is obtained by twisting thin-walled cylinasrs under hydrostatic pressure.

In Fig. 4, these curves have been extended by dashed lines to estimate what the complete failure surface might look like in those regions where data are usually unavailable. At high pressures, the material behaves in a ductile manner and all test types would have the same value of $\tau_{0}$ at failure. At extremely high pressire, $\tau_{0}$ must come to zero as the material melts and can no longer

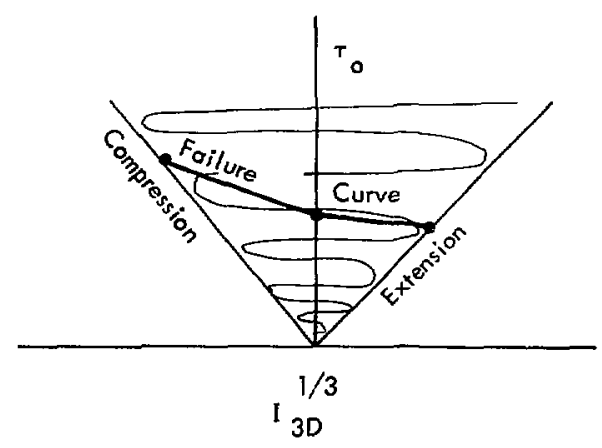

Fig. 3. $\tau_{o}-I_{3 D}^{1 / 3}$ cross uection of the stress space. All possible stress states are within the semi-infinite trough. Possible unfailed states lie below the failure curve.

sustain shear stresses. For negative pressures (tension), typical materials are quite weak. We assume that all the curves converge to the same point $\left(\tau_{0}=0\right)$ on the pressure axis for which the material is in hydrostatic tension. To generate the complete failure surface from the graph of $\mathrm{Fig} .4$, three-termed expansion in terms of $I_{3 D}^{1 / 3}$ for any given value of $P$. Then the coefficients in the expansion are functions of pressure only. The failure surface is then given by

$$
\tau_{0}(\text { failure })=A_{1}(P)+A_{2}(P) I_{3 D}^{1 / 3}+A_{3}(P) I_{3 D}^{1 / 3}
$$

This technique generates a fairly general class of failure surfaces. We use this approach in UKO, although the third $\left(\mathrm{A}_{3}\right)$ term is eliminated because two of the 
principle stresses are always equal in a one-dimensional compurer code the stress state is always compression or extension). The failure surface is specified in the UKO code by specifying values of $\tau_{0}$ as a function of pressure both for compression and extension. The code then generates the pressure-dependent coefficients, $A_{1}$ and $A_{2}$, of Eq. (1).

So far, we have discussed only the mathematical mapping of a failure surface. It should be emphasized that the model assumes that failure is a function of the stress state only, and is independent of path. We must now provide a computational model that simulates stress behavior durin' failure.

We begin by assuming that there exists a continuum of failure surfaces that depend on the state of material. The continuum is bounded by two extremes: a failure surface for consolidated material and a failure surface for rubble. UKO requires that these two bounding failure surfaces be given. All material is assumed to be initially consolidated. At failure, however, the surface changes to some value intermediate between consolidated and rubble. To determine this intermediate surface for each material, RUBF (rubble fraction) is specified in UKO as a function of the pressure at which failure occurs. Thus, for most materials, RUBF $=1$ for failure at regative pressures, and RUBF might be expected to approach 0 as the pressures get large and the rock behaves in a fairly ductile manner. If we assume that $\tau_{0}$ (at failure) is independent of $I_{3 D}^{1 / 3}$ and that the three types give the same $\tau_{0}-P$ relationship, then Fig. 5 shows what these surfaces might look like in a $\tau_{0}-\mathrm{P}$ plot. Note that the rubble surface has been indicated as possessing no strength for negative pressure. If an element of material in Fig. 5 goes from $A$ to $B$ in one time step, the new failure surface is far from $B$ and the stresses must be relaxed. On the other hand, if $P>P_{D}$, the material may be ductile and one might simply limit $\tau_{0}$ so

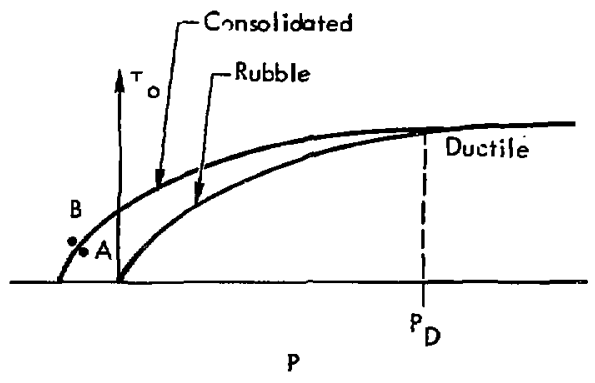

Fig. 5. Comparison of consolidated and rubble failure surfaces. that it cannot go above the failure surface.

Brittle behavior will be defined as the low-pressure stress-relaxation process. Wilkins ${ }^{7}$ has suggested that compute $=$ codes can use tro simple models (dislucation and Maxwell solid) for stress relaxation. UKO also uses a dislocation model in which $\tau_{0}$ is reduced at a constant rate

$$
\dot{\tau}_{o}=-2 G \dot{\gamma},
$$

where $\dot{\gamma}$ (the plastic strain rate) is input to UKO for each material. UKO also uses a modified Maxwell solid model for stress relaxation for brittle failure,

$$
\dot{\tau}_{0}=-\frac{G}{n} \Delta \tau_{0} \text {, }
$$


where $\frac{1}{r_{i}}$ (inverse viscosity) is input for each material, and where $\Delta \tau_{0}$ is the difference between the value of $\tau_{0}$ and the failure surface value of $\tau_{0}$ at the same value of $P$. This simply says that the relaxation rate becomes faster as the stress state is farther from the failure surface.

The values of $\dot{\gamma}$ and $\eta^{-1}$ determine brittle failure stress relaxation rates. However, for ductile failure we simply limit $\tau_{0}$ so it cannot go above the failure suiface. DUCF (ductile fraction) is input to UKO as a function of pressure to determine the mixture 0 : failure mechanisms. One might have DUCF $=0$ for low pressure, and the value of DUCF would go smoothly to 1 as the pressure increases.

In UKO, material melts when a specified specific energy occurs for a given material. As this energy value is approached, the purely solid-like properties of the material vanish. Thus the shear modulus $(G)$, the deviatoric invariants $\left(\tau_{0}\right.$ and $I_{3 D}^{1 / 3}$ ), and the failure surface all approach zero.

When material spalls, the pressures and stresses both relax completely and the shear modulus is set to zero. The UKO code assumes that spall occurs when the specific volume of material exceeds the value of specific volume associated with the minimum pressure that can be sustained by the material according to the failure surface. As material recompacts and positive pressures are achieved, the degree of ductile behavior is used as a criterion to allow the shear modulus to heal so that its full value is regained when the ductility reaches a specified value. The P-V data is then used to calculate the corresponding volume for spall. This spall volume is also used as a criterion for recompaction. If the material recompacts, then it becomes necessary to use the $\mathrm{P}-\mathrm{V}$ data again. It should be noted that the spalling phenomenon involves discontinuous behavior when spalled material is recompacted. We have found that the undesirable noise in the solution for recompaction of spalled material is reduced by the use of artificial viscosity (see "Numerical Considerations"). Typically, a linear q multiplier equal to 0.5 is used for spalled material.

A number of idealized test problems have been run in which the methods of $m$ ixing the failure surfaces (consolidated/rubble) and failure mechanisms (brittle/i. tile) have been varied over reasonable ranges. The resulting variations of velocity fields, displacements, etc., in such calculations have been very small.

The code provides smooth and continuous material behavior (with the exceptions of spall), and solutions converge as zone size is reduced. The scale of the failure description is macroscopic rather than microscopic, and a continuum-mechanics model is used. However, the flexible input format allows the code user to input EOS information in a physically inconsistent way and to include discontinuities in these EOS's. Thus, as is true with almost all computer programs, the code user must appreciate the limits of the model before he can use it profitably. To simulate a real shock wave and the subsequent relaxation, one would need to model the real viscosity (rather than artificial viscosity) aud have the zone size small compared to the shockrise thickness. Then one could also use physically measured values for relaxation rate constants. Unless this is done, the relaxation mechanisms must be considered 
as numerical artifices and close "cousins" of the artiflcial viscosity. Thus, it may be necessary to determine $\dot{\gamma}$ and $\eta^{-1}$ by trial and error to obtain a smooth (non-nois $y$ ) solution. In a wide variety of test problems, however, it was observed that the calculations were not significantly affected by varying $\dot{y}$ and $\eta^{-1}$ cver several orders of magnitude. This indicates that the dominant numorical artiftee is the artificial viscosity, which is discussed in "Numerical Considerations."

Because of the artificial nature of $\dot{\gamma}$ and $\eta^{-1}$, we have found it useful to bypass the brittle description described above for some calculations. This is done by setting DUCF $=1$ for all pressure values. Brittle behavior is then desigwated as the behavior associated with failure that is accompanied by the generation of a new failuse surface. Both models are available to the code user. Who must deternine which is more appropriate for his calculation.

We made UKO calculations (see Appendix) of the Lawrence Livernore Laboratory cratering experiment Pre-Schooner II. Since the code UKO is one-dimensional, the calculation is valid only up to the time at which surface spall occurs. The measured spall (jump-off) velocity was $3.9 \mathrm{~cm} / \mathrm{m}$ sec, and the calculated velocity was $4.0 \mathrm{~cm} / \mathrm{m}$ sec. This agreement is satisfactory when one considers the inhomogeneoss nature of earth materials and the limited infurmation avallable regarding their EOS's.

\section{MUMERICAL CONSIDERATIONS}

This section deals mostly with the numerical technique called artificial viscosity. This method was proposed by Von Neumann and hichtmyer ${ }^{\theta}$ to enable the finite difference equations to simulate the physics associnted with shocks. The artifictal-viscosily method converts the discontinuous functions associated with shocks into rapldly changing (but continuous) functions that the finite-difference method can handle readily. The following form of the so-called "quadratic q" was proposed by Von Neumann and Richtrnyer:

$$
q=\rho\left(C_{1} \Delta x\right)^{2} \quad\left\{\frac{\Delta u}{\Delta x}\right\}^{2} \quad\left\{\begin{array}{l}
\text { For zones being compressed; } \\
\text { otherwise, } q=0
\end{array},\right.
$$

where $\rho$ is density, $C_{1}$ is a constant, $\Delta X$ is zone size, and u is velocity. The $q$ is added to the pressure for each equation in which the pressure appears. (Note that the $q$ depends on the zone size in such a way that it vanishes as the zone size approanhes zero.) The effect of the $q$ is to provide viscous damping over a few zones where $\Delta v \Delta x$ is very large. One of the attractive (and necessary) features of this $q$ is that the Rankine-Hugoniot conditions are preserved for shock descriptions, provided that the preshock and postshock values are not in the few zone reglons over which the shock has been artificially spread. The uko code uses an improved form of q deticribed in Refs. 9 and 10 . For the quadratic form we have the following $a$ 


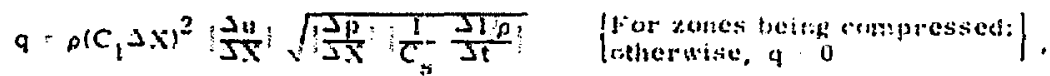

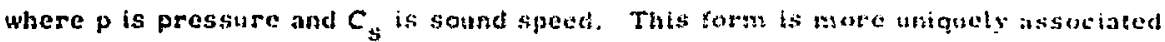
with shocks ond provides smother, moro accumate caleutatians.

The effect of viscosity ireal or artifiall ts to cotvert tinctic cnergy into internal

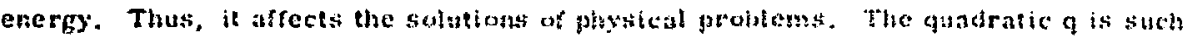
that it introduces insigntficant errors for almust all physical systen:s. Thus, it tis turt necessary to let $2 X$ approach zero to obtain a reasonably accurate computation. For elastic solids, wnfortuately, the quadratic o docs not frovide surficicut smoothing for

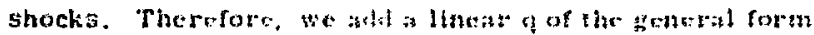

$$
q: p\left(C_{2} \leq x\right) c_{;}|\Delta u|
$$

This form is considecably less senstive to the stecpness of gradicuts. The result is that, In order to smooth the shoch region, mush more atistipation (nonphysical) is introduced into the ealculation as a whole. It is frequently necessary to examine the solution as a runctiot of zone size so that the physical anstwer can be obtained by extrapolating to the case for $\Delta x=0$. Sthee nuost rock mechanies cateulations currenty require a linear 3 . It is essential that the Utio code user be aware of the effect of this

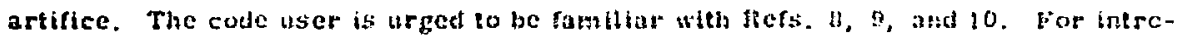
ductory informatiun regarding other methesis of hanfling shochs, the reader is refersed to the text by Richemyer and Marton."

\section{Part II: Numerical Scheme}

\section{MTHODECT:ON}

In the following sections we present, dirt, the difrerence equations of I'KO. Most of these are taken directly from $k O$, are dertued and discussed in llefs. 1 and 7 , and need no further altention here.

Next, we give the logical structure of the entire cude, with a few remarkis on the location and order of the differcnee equations and EOS's tat the coce.

This is followed by a Fortran listing of the important equations that werc changed or adfed in the transformation from kO to UKO: i.e., the equations of artificial viscosity and of the failure model. These constitute the bastc differences between the two codes. The listing is included so that a user may faniliarlye limsalf with these new features in complete detail.

we provide a glossary for the mames in the fortsan listing.

Coples of the code may be made avallable to interested orginizations outsidc I.LL. However, a review and release procedure is required before the code can be transmitted outside the Laboratory. 
OUTLINE OF FINTTE DIFEERENCE EQUATIONS OF UKO

\section{Mass Zoning}

The material is divided into mass intervals:

$$
\begin{aligned}
& m_{j+(1 / 2)}=\frac{p^{0}}{v^{0}}\left[\left(\frac{\left.\left.r_{j+1}^{0}\right)^{d}-\left(r_{j}^{0}\right)^{d}\right]}{d}\right] \begin{array}{ll}
\text { plane: } & d=1 \\
\text { cylindrical: } & d=2
\end{array}\right. \\
& j=1,2, \ldots N
\end{aligned}
$$

\section{Equation of Motion}

$$
r_{j}^{n+(1 / 2)}=U_{j}^{n-(1 / 2)}+\frac{\Delta t^{n}}{\phi_{j}^{n}}\left[\left(\Sigma_{r}\right)_{j+(1 / 2)}^{n}-\left(\Sigma_{r}\right)_{j-(1 / 2)}^{n}\right]+\Delta t^{n}\left(\beta_{j}^{n}\right)(d-1),
$$

where

$$
\begin{aligned}
\left(\Sigma_{r}^{n}\right)_{j+(1 / 2)} & =\left\{-\left[P^{n}+q^{n-(1 / 2)}\right]+s_{1}^{n}\right\}_{j+(1 / 2)} \\
\left(\Sigma_{\theta}^{n}\right)_{j+(1 / 2)} & =\left\{-\left[P^{n}+q^{n-(1 / 2)}\right]+s_{2}^{n}\right\}_{j+(1 / 2)} \\
\phi_{j}^{n} & =\frac{1}{2}\left\{p_{j+(1 / 2)}^{0}\left[\frac{r_{j+1}^{n}-s_{j}^{n}}{v_{j+(1 / 2)}^{n}}\right]+\rho_{j-(1 / 2)}^{0}\left[\frac{r_{j}^{n}-r_{j-1}^{n}}{\left.\left.v_{j-(1 / 2)}^{n}\right]\right\}}\right.\right.
\end{aligned}
$$

$\beta_{j}^{n}=\frac{1}{2}\left\{\left[\frac{\left(\Sigma_{r}\right)_{j+(1 / 2)}^{n}-\left(\Sigma_{\theta}\right)_{j+(1 / 2)}^{n}}{\frac{1}{2}\left(r_{j+1}^{n}+\Sigma_{j}^{n}\right)}\right]\left(\frac{v^{n}}{0}\right)_{j+(1 / 2)}+\left[\frac{\left(\Sigma_{r}\right)_{j-(1 / 2)}^{n}-\left(\Sigma_{\theta}\right)_{j-(1 / 2)}^{n}}{\frac{1}{2}\left(r_{j}^{n}+r_{j-1}^{n}\right)}\right]\left(\frac{v^{n}}{0}\right)_{j-\{1 / 2)}\right\}$.

At an sutside regional boundary $J$,

$\rho_{J}^{n}=\frac{1}{2} \rho_{J-(1 / 2)}^{0}\left[\frac{r_{J}^{n}-r_{J-1}^{n}}{v_{J-(1 / 2)}^{n}}\right]$

$\beta_{J}^{n}=\left[\frac{\left(\Sigma_{r}\right)_{J-(1 / 2)}^{n}-\left(\Sigma_{\theta}\right)_{J-(1 / 2)}^{n}}{\frac{n}{2}\left(r_{J}^{n}+r_{J-1}^{n}\right)}\right]\left(\frac{v_{n}}{\rho_{0}^{0}}\right)_{J-(1 / 2)}$.

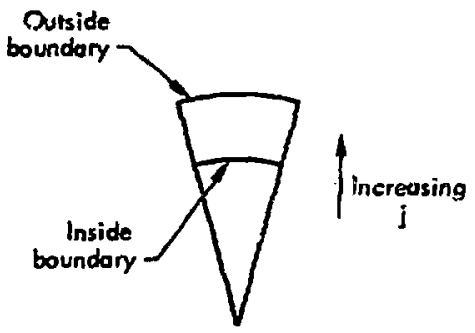


At an in:tide regional boundary $\mathrm{J}$,

$$
\begin{aligned}
& \phi_{J}^{n}=\frac{1}{2} \rho_{J+(1 / 2)}^{0}\left[\frac{r_{J+1}^{n}-r_{J}^{n}}{v_{J+(1 / 2)}^{n}}\right] \\
& \beta_{I}^{n}=\left[\frac{\left(\Sigma_{r}\right)_{J+(1 / 2)}^{n}-\left(\Sigma_{\theta}\right)_{J+(1 / 2)}^{n}}{\frac{1}{2}\left(r_{J}^{n}+r_{J+1}^{n}\right)}\right]\left(\frac{v^{n}}{\sigma}\right)_{J+(1 / 2)} .
\end{aligned}
$$

For a rree surface at $j=3$, the stresses are set to zero at $J+(1 / 2)$ for an outside free surface or at $J-(1 / 2) \mathrm{fcr}$ an inside free surface.

$$
r_{j}^{n+1}=r_{j}^{n}+U_{j}^{n+(1 / 2)} \Delta t^{n+(1 / 2)}
$$

\section{Equation of Continuity}

$$
\begin{aligned}
v_{j+(1 / 2)}^{n+1}=v_{j+(1 / 2)}^{n}+\Delta t^{n+(1 / 2)}\left(\frac{\rho^{f}}{m}\right)_{j+(1 / 2)} & \mid u_{j+1}^{n+(1 / 2)}\left[r_{j+1}^{n+(1 / 2)}\right]^{d-1} \\
& \left.-v_{j}^{n+(1 / 2)}\left[r_{j}^{n+(1 / 2)}\right]^{d-1}+\left[x_{j+(1 / 2)}^{n+(1 / 2)}\right]\right\}
\end{aligned}
$$

$\eta_{j+(1 / 2)}^{n+1}=\frac{1}{v_{j+(1 / 2)}^{n+1}}$; here, $r_{j+1}^{n+(1 / 2)}=\frac{1}{2}\left(r_{j+1}^{n+1}+r_{j+1}^{n}\right)$, etc.

$$
\left[x_{j+(\alpha / 2)}\right]^{*}=\frac{\left[\Delta t^{n+(1 / 2)}\right]^{2}}{12}\left\{\left[u_{j+1}^{n+(1 / 2)}\right]^{3}-\left[u_{j}^{n+(1 / 2)}\right]^{3}\right\} .
$$

Velocity strains:

$$
\begin{aligned}
& \left(\dot{\epsilon}_{1}\right)_{j+(1 / 2)}^{n+(1 / 2)}=\frac{u_{j+1}^{n+(1 / 2)}-U_{j}^{n+(1 / 2)}}{r_{j+1}^{n+(1 / 2)}-r_{j}^{n+(1 / 2)}} \quad \dot{\epsilon}_{2}=c \text { for } d=1 . \\
& \left(\dot{\epsilon}_{2}\right)_{j+(1 / 2)}^{n+(1 / 2)}=\frac{U_{j+1}^{n+(1 / 2)}+U_{j}^{n+(1 / 2)}}{r_{j+1}^{n+(1 / 2)}+r_{j}^{n+(1 / 2)}}
\end{aligned}
$$

\footnotetext{
Correction term for $d=3$ only.
} 


\section{Artificial Viscosity}

Linear q:

$$
\begin{aligned}
& q_{j+(1 / 2)}^{n+(1 / 2)}=C_{L} C_{s}{ }_{j+(1 / 2)}^{n+1} \rho_{j+(1 / 2)}^{n+(1 / 2)} \quad \sqrt{\left[U_{j}^{n+(1 / 2)}-U_{j+1}^{n+(1 / 2)}\right]}
\end{aligned}
$$

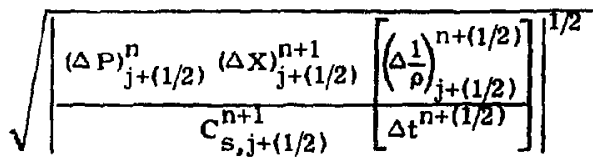

Quadratic q:

$$
q_{j+(1 / 2)}^{n+(1 / 2)}=c_{0}^{2} \rho_{j+(1 / 2)}^{n+(1 / 2)}\left[u_{j}^{n+(1 / 2)}-u_{j+1}^{n+(1 / 2)}\right]
$$

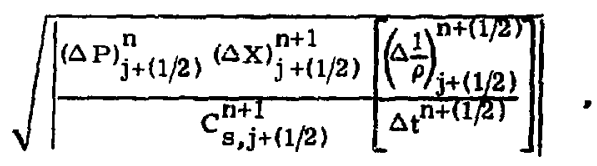

where

$C_{L}$ and $C_{0}^{2}$ are dimensionless constants

$C_{s}$ is sound speed

$\Delta \mathrm{X}$ is zone size

$\Delta P$ is spatial pressure change

$\Delta \mathrm{u}$ is velocity gradient

$\rho$ is density.

\section{Hydrostatic Pressure and Energy}

$$
P_{j+(1 / 2)}^{n+1}=A\left[\eta_{j+(1 / 2)}^{n+1}\right]+B\left[\eta_{j+(1 / 2)}^{n+1}\right] E_{n+(1 / 2)}^{n+1} \text {. }
$$

The change in internal energy, $\Delta \mathrm{E}$, is composed of a hydrodynamic component and a distortion component:

$$
\Delta E=-(P+q) \Delta V+\Delta Z
$$

Change in distortion energy, $\Delta \mathrm{Z}$ :

$$
(\Delta z)_{j+(1 / 2)}^{n+(1 / 2)}=v_{j+(1 / 2)}^{n+(1 / 2)}\left[s_{1} \dot{\epsilon}_{1}+(d-1) s_{2} \dot{\epsilon}_{2}\right]_{j+(1 / 2)}^{n+(1 / 2)} \Delta t^{n+(1 / 2)},
$$


where

$$
s_{1}^{n+(1 / 2)}=\frac{1}{2}\left(s_{1}^{n+1}+s_{1}^{n}\right) \text {, etc. }
$$

Total internal energy, E:

$$
(E)_{j+(1 / 2)}^{n+1}=\left(\frac{E^{n}-\left\{(1 / 2)\left[A\left(\eta^{n+1}\right)+P^{n}\right)+\bar{q}\right]\left[v^{n+1}-V^{n}\right]+\Delta z}{1+(1 / 2)\left[B\left(\eta^{n+1}\right)\right]\left[v^{n+1}-v^{n}\right]}\right)_{j+(1 / 2)} .
$$

where

$$
\bar{q}=(1 / 2)\left[q^{n+(1 / 2)}+q^{n-(1 / 2)}\right] .
$$

This equation assumes that the EOS has the form

$$
P=A(n)+B(\eta) E .
$$

In most practical calculations, iteration is required in the routine to obtain both energy and pressure.

\section{Stress and Failure Calculation}

Calculate $\mu$, the shear modulus $(\mu-0$ as material melts or if it spalls). Stress deviators:

$$
\begin{aligned}
& \left(s_{1}\right)_{j+(1 / 2)}^{n+1}=\left(s_{1}\right)_{j+(1 / 2)}^{n}+2 \mu\left\{\left(\dot{\varepsilon}_{1}\right)_{j+(1 / 2)}^{n+(1 / 2)} \Delta t^{n+(1 / 2)}-\frac{1}{3}\left[\frac{v^{n+1}-v^{n}}{v^{n+(1 / 2)}}\right]_{j+(1 / 2)}\right\} \\
& \left(s_{2}\right)_{j+\{1 / 2)}^{n+1}=\left(s_{2}\right)_{j+(1 / 2)}^{n}+2 \mu\left\{\left(\dot{\varepsilon}_{2}\right)_{j+(1 / 2)}^{n+(1 / 2)} \Delta t^{n+(1 / 2)}-\frac{1}{3}\left[\frac{v^{n+1}-v^{n}}{v^{n+(1 / 2)}}\right]_{j+(1 / 2)}\right\} \\
& \left(s_{3}\right)_{j+(1 / 2)}^{n+1}=-\left[\left(s_{1}\right)_{j+(1 / 2)}^{n+1}+\left(s_{2}\right)_{j+(1 / 2)}^{n+1}\right]
\end{aligned}
$$$$
\sqrt{\left(s_{1}^{2}+s_{2}^{2}+s_{3}^{2}\right)(2 / 3)}={ }^{7} \text { oct } . \quad \text { octahedral shear stress }
$$

If $\tau_{\text {oct }} \leq Y 2 F$, the material is within the elastic limit. If not, the material is failing. If the material is failing, determine the new rubble fraction $R U B F(P)$. Ther, calculate the new fallure surface value of $\tau_{0}$, Y2F $=$ RUBF $*$ Y2FRUB + (1-RUBF) Y2FCON. Y2FRUB and Y2FCON are the rubble and consolidated failisre surfaces, respectively. 
If the material is falling, use DUCF (the fraction of failure that is ductile rather than brittle) to relax the atresses.

$$
\begin{aligned}
& \tau_{\text {oct }}=\text { DUCF Y2F }+(1-\text { DUCF })\left(\tau_{\text {oct }}-\dot{\gamma} \mu \Delta t-\frac{\mu}{\eta} \mid \tau_{\text {oct }}-\text { Y2F } \mid \Delta t\right) \\
& \dot{\gamma} \text { is a relaxation rate constant of a dislocation type, } \\
& \eta \text { is a viscous constant for a Maxwell solid-like relaxation model. }
\end{aligned}
$$

However, do not permit $T_{\text {oct }}$ to become smaller than Y2F. Likewise, reiax the pressure, if necessary.

Test to see if the spall condition has been met. If it has, set a sentinel to skip the EOS routine.

\section{Stability}

$$
\begin{aligned}
& \Delta t^{n+(3 / 2)}=\left.\frac{2}{3} \cdot \frac{\Delta r^{n+1}}{\sqrt{a^{2}+b^{2}}}\right|_{\min \text { over } j} \\
& \Delta r^{n+1}=r_{j+1}^{n+1}-r_{j}^{n+1}
\end{aligned}
$$

where

$$
\begin{aligned}
a & =\text { sound speed } \\
b & =8 c_{0}^{2} \Delta r^{n+1}(\dot{v} / V)^{n+(1 / 2)} \\
c_{0} & =0 \text { if } \dot{v} / V \geq 0 .
\end{aligned}
$$

If $\Delta t^{n+(3 / 2)}>(1.4) \Delta t^{n+(1 / 2)}$, uge $\Delta t^{n+(3 / 2)}=(1.4) \Delta t^{n+(1 / 2)}$.

$$
\Delta t^{n+1}=\frac{1}{2}\left[\Delta t^{n+(3 / 2)}+\Delta t^{n+(1 / 2)}\right] \text {. }
$$


LOGICAL STRUCTURE OF TTKO; CODE BLOCKS, SUBROUTINES, AND THEIR PURPOSES

MAIN

aUl MAKE DROP FILE, CLEAR LARGE CORE CCMMON. aLSE INCLULES COMMON ANO MOST CATA STATERENTS IN A CLICHE.

GENERATOR (SEGMENT 1 )

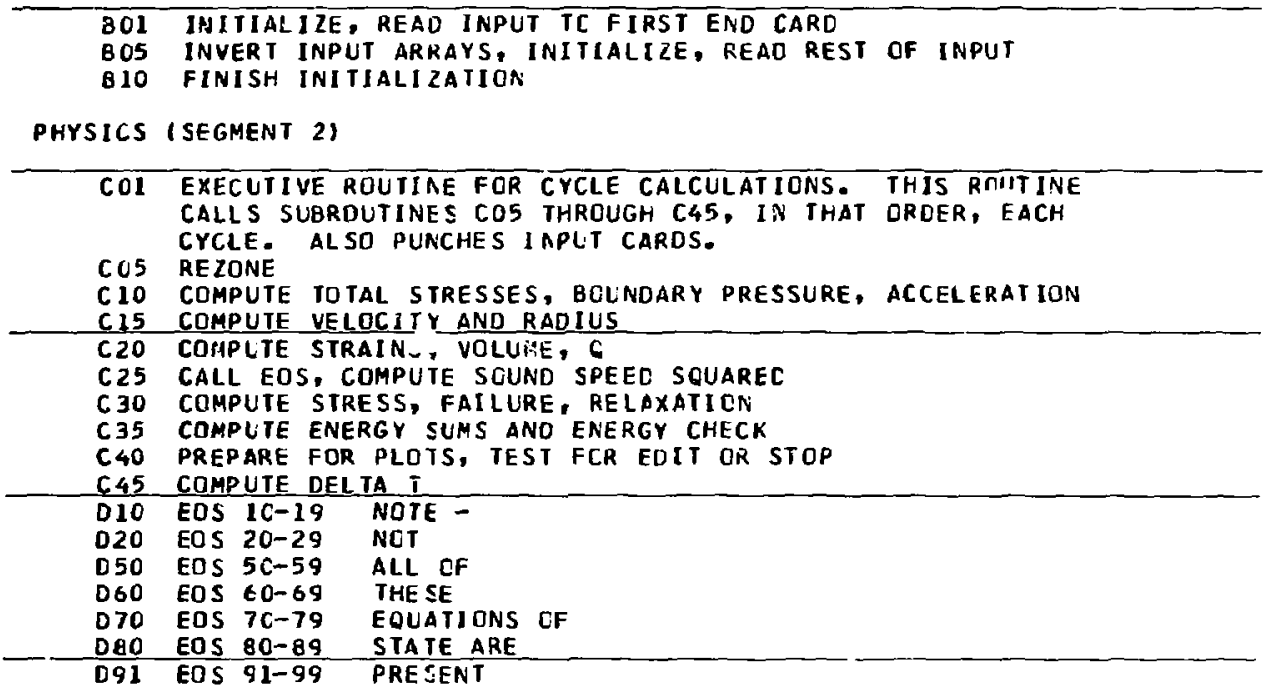

\section{DUTPUT (OVERLAY)}

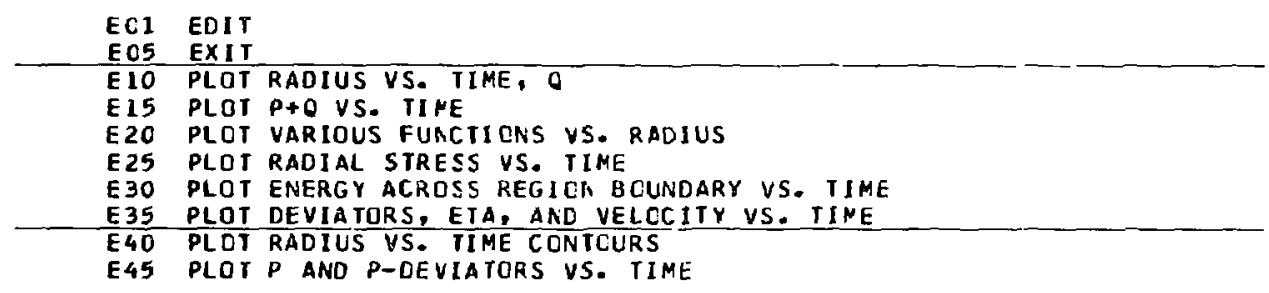

The difference equations are located in subroutines C10-C35 and C45. They occur there in the order in which they are listed in Section B, Outline of Finite Difference Equations in UKO.

Equations of state are located in subroutines D10-D91. They are represented as polynomials $(P=P(\mu, E]$ ), ideal gas equations, Tillotson equations, Mie-Grüneisen equations, and others. 
LISTING OF SUBROUTINES FOR ARTIFICIAL VISCOSITY AND FAIZURE MODEL

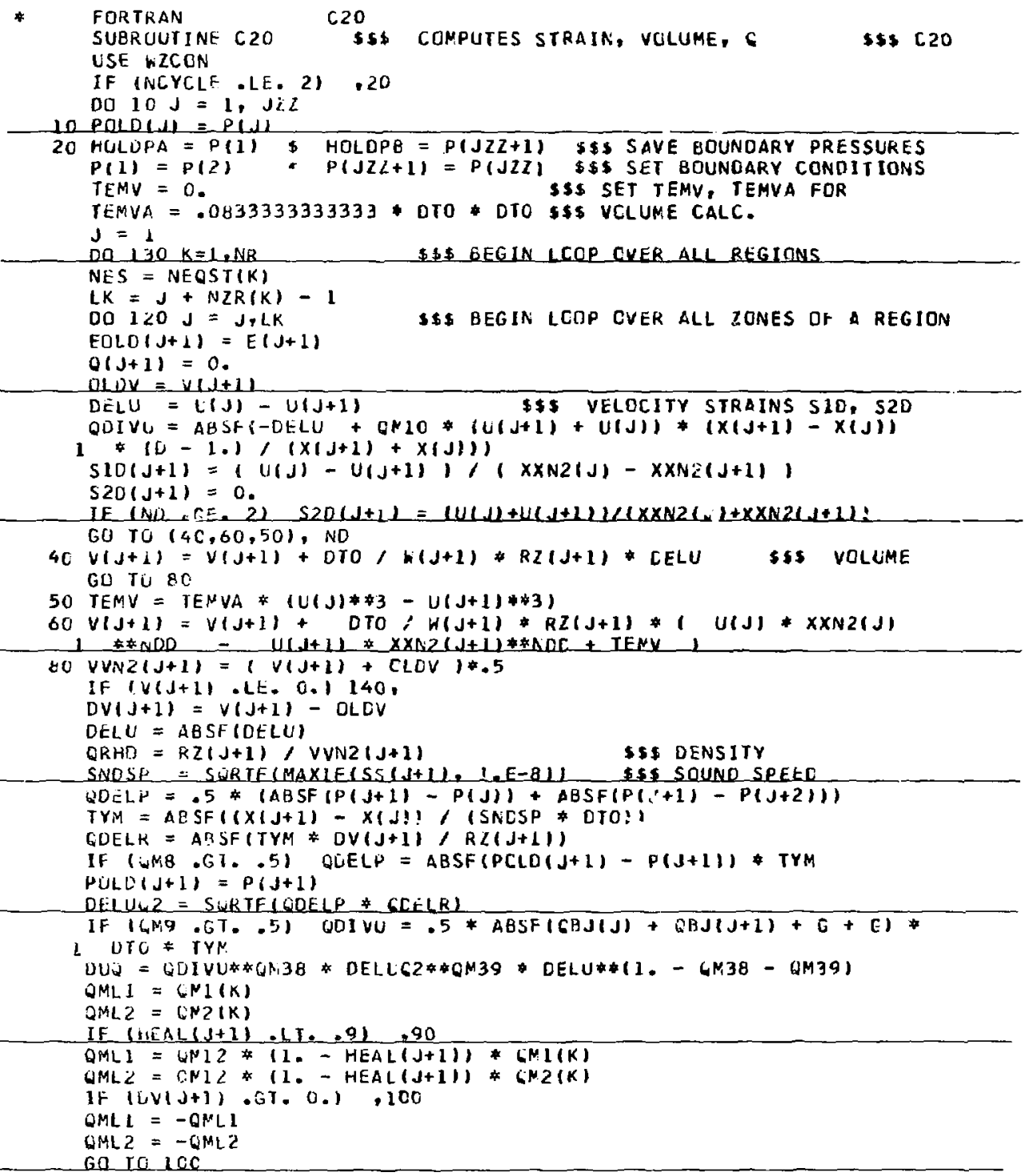

90 If (UV $(J+1)$, GT. $0.1,100$ 


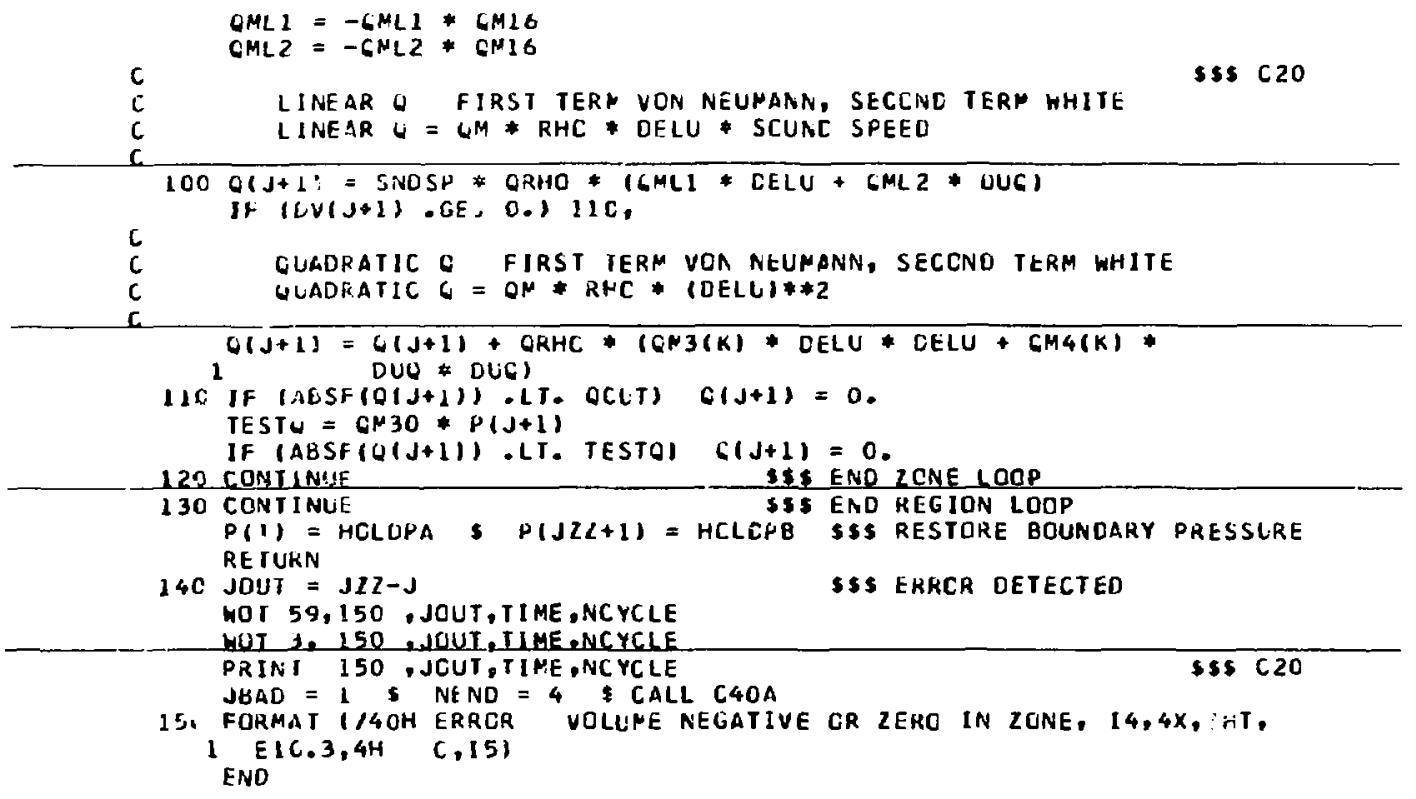




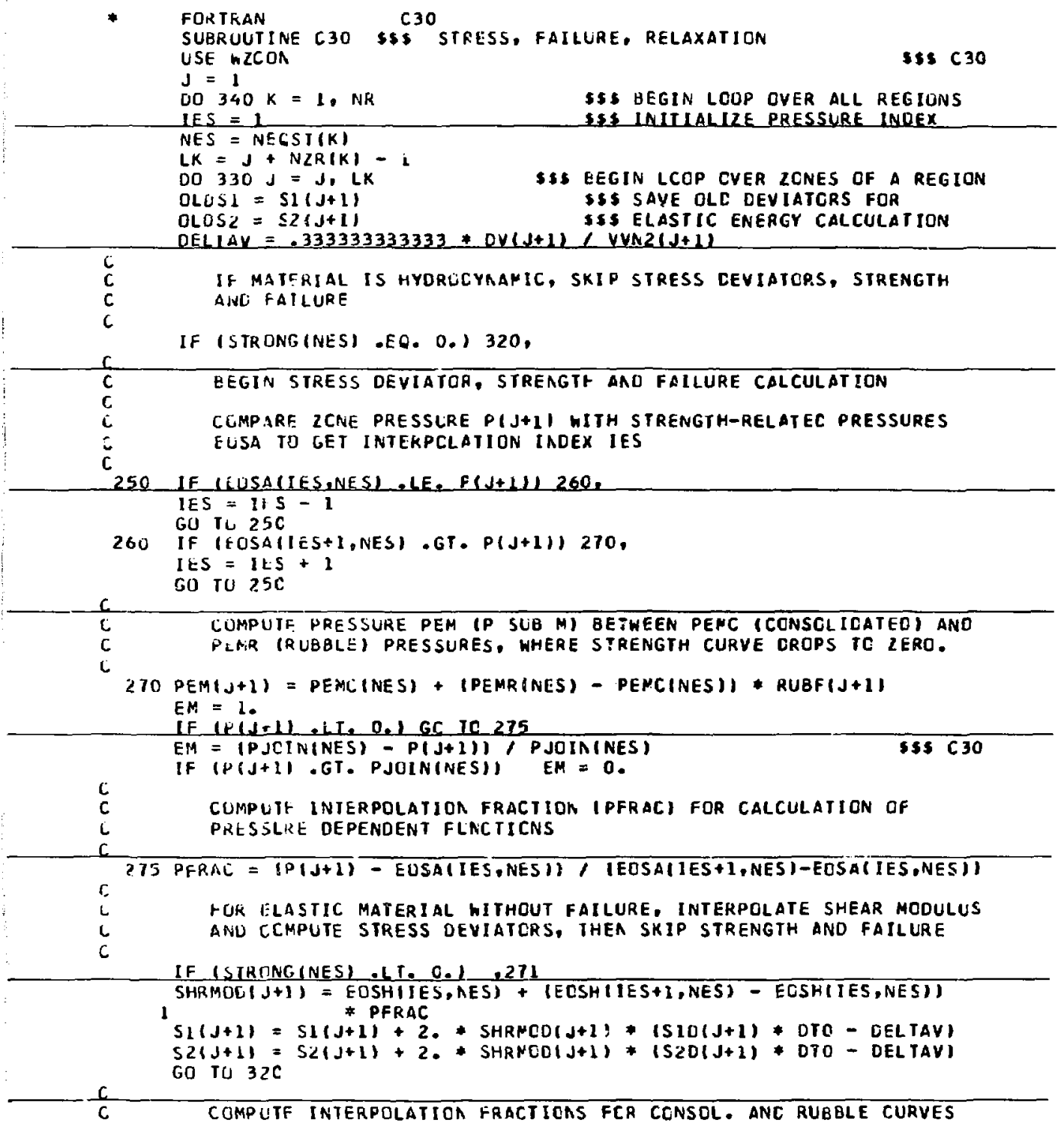




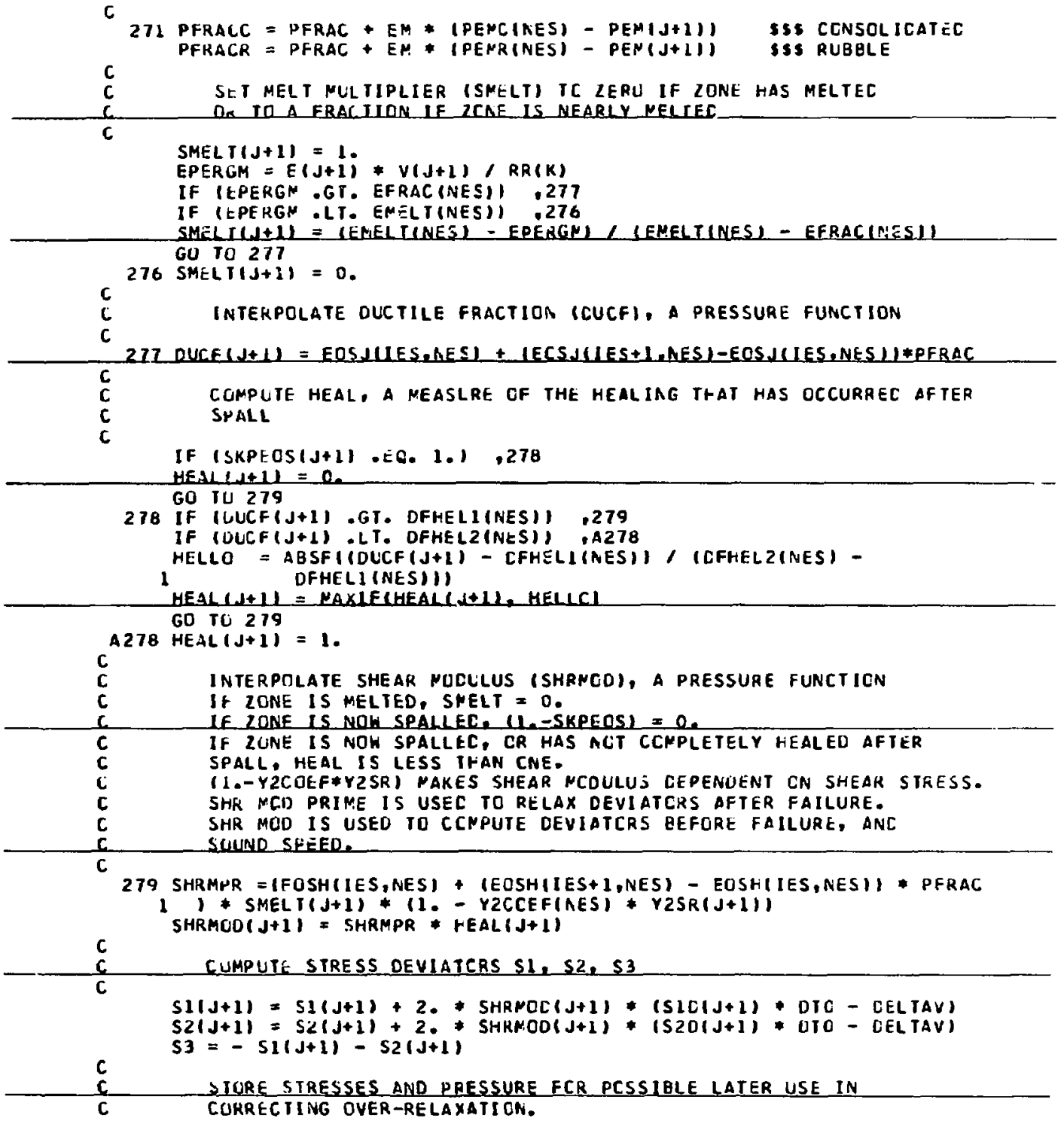




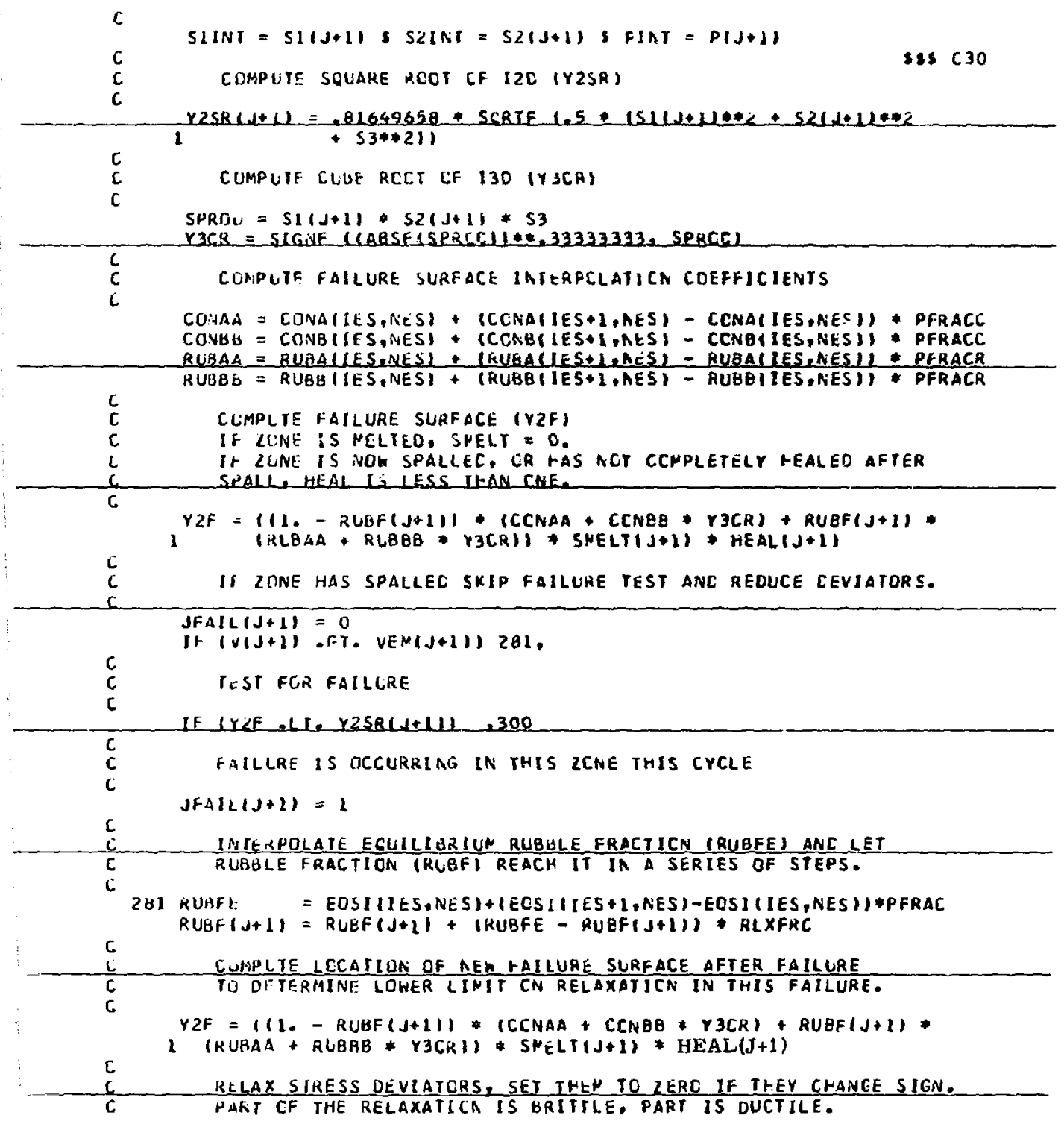


C

RËUULL $=51 G 55=0$.

s\$s 630

IF $|Y 2 S K| J+1)$. RE. $0.1,282$

REDULE = Y $2 F / Y 2 S R(J+1)$

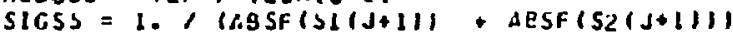

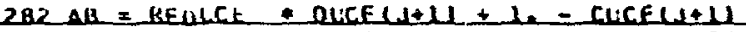

CV $=11$. - DLCF $(J+11)$ E EO - SHANPR * SIGSS *13. EOSYINESI

1 (1. - hEUUCE) * EQSZ(NES) - Y2SR(J+11)

If $(S 1(\mathrm{~J}+1), E$. 0.0.$) 283$,

SIHN $=1 . \quad$ SIHN $=$ SIGAF $(S I H N, S I I J+11)$

CO1 $=C j * A B S+(S 1(J+1))$

If ICDL GI. ERACSIACWESU COL a ERACSTRLNES)

$S I(J+i)=S(1)+1) * A B-\operatorname{CDl} * S I+N$

If $(S I(J+1)$ * SIHN - LT. 0.1 SI J+I) $=0$.

283 Ir $(2,1 j+1)$ EQ E. O.) 284 ,

$\operatorname{SIMN}=1 . S$ SIHN $=$ SIGNF $(S I H N, S 2(J+1))$

$C D 2=C D * A B S F(S 2(j+1))$

IF ULO2 GT. FRACSTRINESU CO2 I ERACSIRLNES)

$S 2(J+1)=S 2(J+I)+A B-\operatorname{CD}+S 1+A$

If $(S L I J+1)+S I H N \cdot L T \cdot C.) \quad S 2(J+1)=0$.

C

KELAX PRESSURE, SET IT TC ZERC IF IT CHANEES SIGN

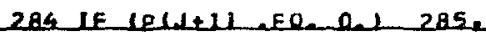

$S ! H N=1$. S SIHN = SIGNFISIHN, PIJ+III

$C D=11$ - DLCF $(J+1)) *$ CTO * SHRMPA

DP = EOSL(NES) * CD * 13. * ECSYINES) + AUSF(PIJ+1)) ECSZ(NES))

IF $(P(J+1) \cdot G T .0) \quad D P=.-[P * 6 N 27$

$P(J+1)=\operatorname{DLCF}(J+1) * P(J+1)+(1+-\operatorname{CUCF}(J+1)) *(P(J+1)+[P($

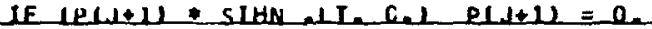

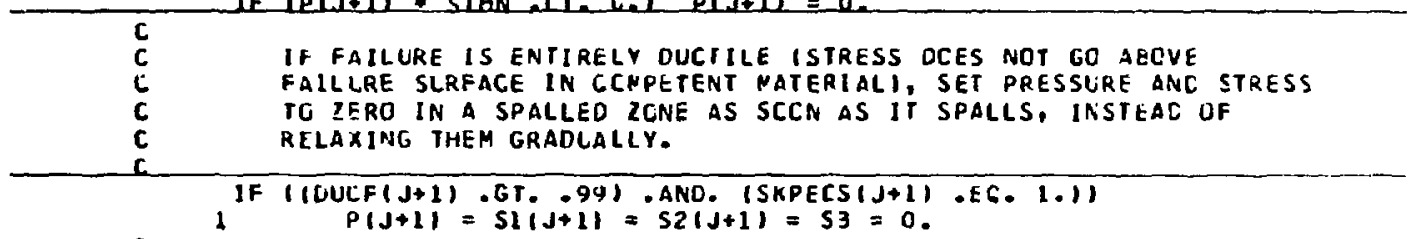

$\begin{array}{ll}C & \text { TEST FOR CVER-RELAJATION ANC ACJUST CEVIATORS ANO PRESSURE } \\ \text { C } & \text { IF NCEDEO. }\end{array}$

IF $(P(J+1), G T \cdot 0)$.

$S 3=-S 1(J+1)-S 2(J+1)$

Y2SRN $=.81649658 *$ SCRTF $1.5 *(S 1(J+1) * 2+52(J+1) * * 2+53 * * 2) 1$

IF (YZSRN - LT. YZF) .285

FRCINT $=A B S F(Y 2 S R(J+1)-Y Z F) / A B S F(Y 2 S R(J+1)-Y 2 S R N)$

SI $(J+1)=$ SLINT + FRCINT $($ SI $(J+1)-$ SIINT)

$S 2(d+1)=S 2 I N T+F R C I N T *(S 2(J+1)-S 2 I N T)$

$P(J+1)=P I N T+F R C I N T+(P(J+1)-P I N T)$

$\$ \$ \$ 130$

C

COMPUIE RÉLAXED STRESS AFTER FAILLRE, USING RELAXEC CEVIATORS

$285 S 3=-51(N+1)-52(1+1)$

$Y 2 S R(J+1)=.01649658 *$ SCRTF $1.5 *(S 1(J+1) * 2+52(J+1) * * 2$ 
C

C

COMPUTE SPALL PRESSURE PEP ANC CCRRESPONCING SPALL VOLUME VEM.

PEN $(J+1)=\operatorname{PEMC}($ NES $)$ + $\operatorname{PEMR}(N E S)$ - PEMC(NES) * RUGF $(J+1)$

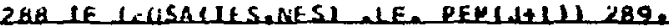

IES $=$ IES - I

GG 10288

289 IF IEUSAIIES+1, NESI. GT. PEFIJ+III 290 ,

IES $=1 F \mathbf{S}+1$

GO TU 288

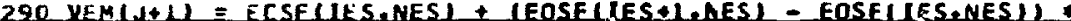

1 (P[MIJ+1) - EOSA(IES,AES) / (EQSAIIES+1,NES) - EOSA(IES,NES)

$2+1 . E-100\}$

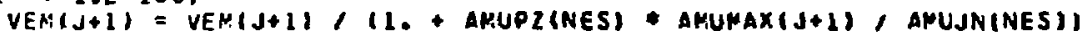

C SET SKIP-EOS SENTIMEL IF ZONE VCLUNE Y IS GREATER THAN SPALL

C VUIUME YEV. THIS SHA INEL MAY BE SET THIS CYCLE EYEN IF

C FAILURE DID NCT OCCUA THIS CYCLE. BECAUSE YEH WOULD HAYE BEEN

C CUHPLTEU IN ANY PREVICUS CYCLE IN HHICH FAILURE OCCURREC.

C

300 SKPEUS $(J+1)=0$.

IF $(V(J+1), G T, V E M(J+1), 310$

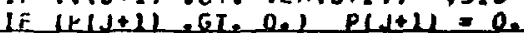

SKPEUS $(J+1)=1$.

$\$ \$ \$ 30$

C CCIMPUTF NEH SHEAR NOCULUS AFTER FAILURE

C 310 SHRMUL $(J+1)=$ (EOSHIIES,AES) + (ECSH(IES+1,NES) - EOSHIIES,NESI)

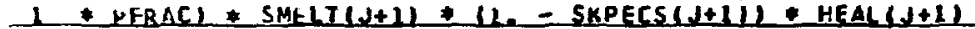

C

C

EILL OF STRENGTH, FAILURE, RELAXATION CALCULATION

320 VCr $=. S *$ VYN2 $(J+1) * C$ TO

$E(1 J+1)=V D T *(S I(J+1)+0 L D S 1) *$ SLD(J+1) S\$\$ ELASTIC ENERGY

$E 2(\lambda+1)=407 *(52(d+1)+E(D S 2) * 520(d+1) * D C$

$E \mid T(J+1)=E I T(J+1)+E(I J+1)$

$E 2 T(J+1)=E 2(J+1)+E 2(J+1)$

$E(J+1)=[0(D) J+1)-.5 * 0 V(J+1) *(P(J+1)+\operatorname{POLC}(J+1)+0 Q(J+1)$

1

$+\theta(J+1))+E(j+1)+E 2(j+1)$

330 CUIVI LNUE

340 CUNT LNUt

\$\$S ENC ZONE LOOP

RETURN

ss ENC REGION LOOP

END

$\$ \$ 5 C 30$ 
CONAIP, EUS) FAILURE SURFACE COEFFS. OF CCASULIDAIED SIRENGIH CURVES AT INPUT VALUES GF STRENGTH CLRVES.

CONAA FAILURE SURFACF. INTERPOLATION COEFFICILNTS OF CCASOLIDATEL STRENGTH CURVES IEOSB, EOSLI INTERPOLATLO BETHEEN INPUT VALUES OF STRENG IH CURVES.

CONBIP,EOSI FAILURE SURFACE COEFFS. OF CCASOLIDATEU STRENGIH CURVES AT INPUT VALUES OF SIRENG IH CLRVES.

COMBB FALLURE SURFACE INTERPOLATION COEFFICILNTS OF CCNSOLIDATED STRENGTH CURVES (EOSB, ECSC) INTERPQLATED BETWEEN INPUT VAL UES OF STRENG IH CURVES.

D 1. PLANE, 2. CVLINDER, 3. SPHERE

DD O. PLANE, I. CYLINDEK, 2. SPHERE

DELU SPATIAL VELQCITY DIFFERENCE.

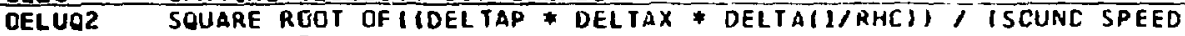
* deltatil in Q calc.

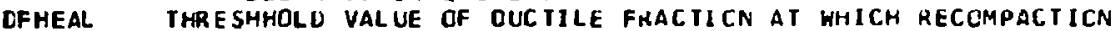
BEgINS TU HEAL a SPALLE ICNe. AT THIS VAlUE CF CUCT ILE FRACTION THE SHEAR MODULUS CF THE SPALLED ZCNE BEGINS TO RETURN FROM ZERO TG ITS NCRHAL VALUE. SHEAR NCDULUS HILL REACH ITS NORMAL VALUE WHEN DLCTILE FRACTICN REACHES 1. OPTIONAL INPUT. OEFALLT $=.5$

DP PRESSURE CHANGE IN RELAXING IN bRITTLE FAILURE, D FUNCTION OF SHEAR MGDULUS SHMPR, DISLCCATION NOOEL FAILURE RATE ECSY, ANO RECIPROCAL OF MAXHELL VISCOSITY EOSZ.

DTO CELIA I ITIME STEPL AT IHIS CYCLE.

DUCF DUCTILE FAILURE FRACTION, THE FRACTICN CF FAILURE WHICH IS DUCTILE RATHER THAN BRI ITLE. A PRESSURE FUNCTIDN.

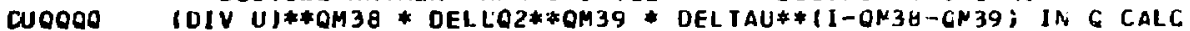

OV $(J+1) \quad V(N+1)-V(N)$ FOR 2 CNE $J+1 / 2$

E SPECIFIC INTERNAL ENERGY CF ZCNE.

EOLO SPECIFIC INTERNAL ENERGY OF ZONE IN PREVIOUS CYCLE.

EFRACIEOSI FRACTJCN USED IN MELT TEST. IN INPUT, EFRAC IS A PURE NUMBER IDEFAULT = .81, IA GEAERATCR, EFRAC EECOMES D FRACTIONAL PART OF THE MELT EAERGY IEFRAC = EFRAC * EMELTI. SEE EMELT.

EM

a FRACTION USED IN INTERPOLATING FAILURE SUR'FACE CDEFFICIENTS.

EMELTIEOS) MELT ENERGY (PER GRAM) OF A MATER IAL, THE ENERGY REQUIREC TI RAISE TEMPERATLRE TO MELTING PCINT, PLUS HEAT OF FUSICN. USED TO DEC IDE WHETHER A ZCNE HAS MELTED. DEFAULT $=1$. E 10

EOSA(EOS) PRESSURE TABLE FOR STRENGTH, FAILURE, ANU RELAXATICN CALC. EOSB(P.EOS) CONSOLIDATED COHPRESSIVE STREAGTH CURVE.

EOSF(P,EOS) ORIGINAL VOLUME CLRVE (LQADIRG ClURVE).

EOSH(P,EOS) SHEAR MODULUS.

EOSIIP, EOS) RUBBLE CURVE FRACTION, THE FRACTICN OF THE CCNPOSITE STRENGTH CUR VE WHICH IS MADE UP OF THE (INPUT) RUEBLE STRENGTH CURVE RATHER THAN THE (INPUT) CCASCLICATED STRENGTH CURVE.

EOSJ(P,EOS) OUCTILE (VON MISES) FAILURE FRACTION, IHE FRACTICN DF FAILURE WHICH IS DUC TILE RAIHER THAN ERITTLE.

EOSUIEOSI PRESSURE RELAXATION MULTIPLIER. DEFAULT = I.

EOSYIEOS) DISLOCATION MODEL (ERITTLEI FAILURE RATE, GAMMA COT. DEFAULT $=1 . E 10$ 
EOSZIEOSI RECIPROCAL OF MAXWELL VISCOSITY, I/ETA, USED IN RELAXATION AF TER BRITTLE FAILLRE.

EPERGM ENERGY PER GRAH IN A ZONE, USED IN MELT TEST.

EIIJ) ELASTIC ENERGY OF ZCNE IRADIAL DIRECTION) ADCED THIS CYCLE.

EIT(J) ELASTIC ENERGY OF ZONE (RADIAL DIRECTION) SUMMED DVER TIME.

EZ(J) ELASTIC ENERGY OF 2ONE (TANGENTIAL OIRECTION) ADCED THIS CYCLE

E2TIJ) ELASTIC ENERGY OF ZONE (TANGENTIAL DIRECTION) SUMMED OVER TIME

FRACSTR FRACTION OF MAX. OF CONSOLIOATED COMPRESSIVE STRENGTH CURVE (EOSB). SEE EOST.

FRCINT A RATIO OF STRESS DIFFERENCES, USED IN RECALCULATING OVERRELAXED STRESSES AND PRESSURE AFTER FAILURE

HOLDPA TEMPORARY STORAGE FOR OUTER BOUNOARY PRESSURE IN THIS RCUT INE

HOL DPB TEMPORARY STORAGE FOR INNER BOUNDARY PRESSURE IN THIS ROUT INE

IES INDEX OF PRESSURE TABLE (EOSA)

$J$ INDEX OF ZONES ANO ZONE INTERFACES

$K$ INDEX OF REGIONS

LK NO. OF ZONES IN THIS REGION

MU II-VI/V, HHERE V IS RELATIVE SPECIFIC VOLUME

MUJOIN MU VALUE AT HHICH LCADING AND UNLOADING P VS. MU CURVES JOIN.

MUMAX MINIMUM OF (MAX. MU EVER REACHED BY THIS ZONE, OR MUJOIN)

MUPZ MU AT FOOT DF UNLOADING P US. MU CURVE.

NCYCLE GYCLE NUMBER OF PROBLEM.

ND 1 PLANE 2 CYLINOER, 3 SPHERE

NDD O PLANE, 1 CYLINOER: 2 SPHERE

NEOSTIK) EOS OF REGION

NES EOUATION OF STATE OF CURRENT REGIDN

NR NUMBER OF REGIDNS TO BE CALCULATED THIS CYCLE

NZRIK) NUMEER OF ZONES IN REGION K

CLDV RELATIVE SPECIFIC VOLUAE AT LAST PREVIOUS CYCLE.

P PRESSURE IN ZONE THIS CYCLE

PEM PRESSURE AT HHICH STRENGTH CURYE OF THIS ZONE THIS CYCLE

INTERSECTS PRESSLRE AXIS - THAT IS, PRESSURE AT WHICH STRENGTH GOES TO ZERD. THE STRENGTH CURVE WILL BE SOHE CCMBINATION OF THE INPUT CONSCLIOATEO STRENGTH CURVE ANO THE INPUT RUBBLE STRENGTH CURVE, SO PEA HILL COINCIDE WITH PEMC DR PEMR OR LIE BETHEEN THEH.

PEMC PRESSURE (P SUB H. CONSDLIDATEOI IN PRESSURE TABLE (EDSA) CORRESPONDING TO LAST ZERO VALUE IN CONSOL. CCMPRESSIVE STRENGTH CURVE (EOSB) - PRESSURE AT HHICH CONSCLICATEC COMPRESSIVE STRENGTH CURYE ORCPS TO ZERO.

PEMR PRESSURE (P SÜG $M$. RUBBLE) IN PRESSURE TABLE (EOSA) CORRESPONDING TO LAST ZERO VALUE IN RUBBLE COMPRESSIVE STRENGTH CURVE (EOSO) - PRESSURE AT HHICH RUBRLE COMPRESSIVE STRENGTH CURVE DRCPS TO ZERD.

PFRAC RATIO OF PRESSURE DIFFERENCES, USED TO INTEROPOLATE VARIOUS FUNCTIONS OF PRESSURE SUCH AS STRENGTH ANC SHEAR MOCULUS.

PFRACC MODIFIED FORM OF PFRAC, USED TO INTERPOLATE CONSOLIDATED STRENGTH.

PFRACR MODIFIED FGRM OF PFRAC, USED TO INTERPOLATE RUBGLE STRENGTH.

PINT TEMPQRARY STORAGE FCR PRESSURE JUST BEFERE FAILURE CALC. IT MAY BE USED AFTER FAILURE TO RECALCULATE AN OVER-RELAXED PRE SSLIRE.

PJOIN

POL. D

PRE SSURE IN EOSA TAELE AT MHICH CONSCL. AND RUBBLE COMPRESS IVE STRENGTH CURVES BECOME EQLAL

PRESSURE IN ZONE AT LAST PREVIOUS CVCLE 
QIJ) ARTIFICIAL VISCOSITY IN ZONE J-1/2

QBJIJ) ACCELERATION OF INTERFACE J

OCUT

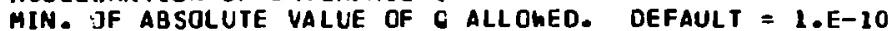
A Q SHALLER THAN THIS WILL OE SET IO ZERO AS SCON AS IT IS COMPUTED.

QDIVU DIVERGENCE OF U (VELOCITY), USED IN O CALC.

OML 1 COEFFICIENT OF VON NEUHANN TERM IN LINEAR $G$.

GHL 2 COEFFICIENT OF WHITE TERM IN LINEAR G.

QM 1 A FACTOR IN QML1, THE COEFF. OF VCN NEUMANN TERM IN LINEAR O. OPTIONAL INPUT. DEFAULT $=0$.

QH2 A FACTOR IN QML2, CCEFF. OF WHITE TERM IN LINEAR G. OPTIONAL INPUT. DEFAULT $=.1$

QH3 COEFFICIENT OF VON NEUMANN TERM IN QUADRATIC O. CPTIONAL INPUT. OEFAULT $=0$.

QM4 CDEFFICIENT DF WHITE TERH IN QUADRATIC O. CPTIONAL INPUT. DEFAULT $=3$.

QM 8 SENTINEL IN Q CALC. IF GREATER THAN - 5, IT WILL CAUSE RECALCULATION DF GODELP. OPTIONAL INPUT. DEFAULT = 0 .

ON9 SENTINEL IN Q CAL.C. IF GREATER THAN -5, IT HILL CAUSE RECALCULATION OF GOIVU IDIVERGENCE OF YELOCITY). OPTIONAL INPUT. DEFAULT $=0$.

OH10 COEFFICIENT IN ODIVL (OIVERGENCE DF VELOCITY) CALC. OPI IONAL INPUT. DEFAULT $=1$.

OH 12 FAC TOR IN COEFFICIENT OF VCN NEUMANN AND WHITE TERMS IN LINEAR Q. USED ONLY VIHEN ZONE 15 SPALLED OA WHEN IT HAS NCT HEALED COHPLETELY AF TER A SPALL. OPTIONAL INPUT. DEFAULT $=5$.

ON16

FAC TOR IN COEFFICIENT OF VCN NEUMANN AND WHITE TERMS IN LINEAR Q. USED ONLY MHEN ZONE IS EXPANDING AND IS NEITHER SPALLED NOR HEALING. OPTIONAL INPUT. DEFAULT $=2$.

QM 30 COEFFICIENT OF ZONE PRESSURE IN O CUTOFF TEST. CPTICNAL INPUT. DEFAULT $=.002$ SEE TESTC.

QH38 EXPDNENT IN HHITE TERM IN OUADRATIC G. OPTICNAL INPUT. DEFAULT $=.54$

QH39 EXPONENT IN WHITE TERM IN QUADRATIC C. CPTICNAL INPUT. DEFAULT $=.45$

QH27 COEFFICIENT OF PRESSURE CHANGE IR RELAXATION AFTER ERITTLE FAILURE. USED ONLY HHEN PRESSURE IS GREATER THAN ZERO. (SEE DP) OPTIONAL INPUT. DEFAULT = 0 .

QO O FRDM LAST PREVIQUS CYCLE.

QODELP DEL TA PRESSURE (SPATIAL DIFFERENCE) IN Q CALC.

QQDELR DELTA(X) * DELTA(1/RHQ) / (SCUND SPEED * DELTA T) IN Q CaLC.

QQQRHO PRESENT DENSITY OF ZCNE IN Q CALC.

REDUCE FAILURE STRESS Y2F DIVIOED BY APPLIED STRESS YZSR. USEC TO CALCULATE STRESS DEVIATOR RELAXATION AFTER FAILURE.

RLXFRC RELAXATION FRACTION, A COEFFICLENT IN CALC CF RUBBLE FRAC TION. CAN BE USED TO LET RUBBLE FRACTICN REACH ITS EQUILIBRIUM VALUE OYER AN EXTENDED TIME. OPTIONAL INPUT. DEFAULT $=1$.

RUBFE EQUILIBRIUM VALUE OF RUBBLE FRACTICN. SEE RLXFRC.

RZ REFERENCE DENSITY OF ZONE.

SHRMOD SHEAR MODULUS. USEO TO COMPLIE DEVIATORS BEFORE FAILURE. ANC SOUND SPEED.

SHRMPR SHEAR MODULUS PRIME. SIMILAR TO SHRMOD BUT IS UNAFFECTED BY SPALL OR HEALING AFTER SPALL. USEO TC RELAX CEVIATORS 


\begin{tabular}{|c|c|}
\hline $\begin{array}{l}\text { SIGNF } \\
\text { SIHN }\end{array}$ & $\begin{array}{l}\text { AFIER FAILURE. } \\
\text { SIGN FUNC IION. SUPPOSE A }=\text { SIGNF }(B, C) \text { THEN A WILL HAVE THE } \\
\text { MAGNITUDE OF B ANO THE SIGN OF C. } \\
\text { IEMPORARY STORAGE FOR THE ALGEQRAIC SIGN OF VARIOUS QUANTITIES }\end{array}$ \\
\hline $\begin{array}{l}\text { SNOSPD } \\
\text { SPL SEN }\end{array}$ & $\begin{array}{l}\text { SOUND SPEED } \\
\text { SPALL SENTINEL, A FRACTION. II-SPLSEN MULTIPLIES THE SHEAR } \\
\text { MODULUS AND IS A MEASURE CF THE HEALING THAT HAS CCCURREC } \\
\text { AFTER SPALL. WHEN SPLSEN IS GREATER THAN O I. THE LINEAR } \\
\text { O COEF ICIENT IS INCREA SED TO REDCE THE NCISE INHERENT IN } \\
\text { THE RECOMPACIION OF SPALLED MATERIAL. }\end{array}$ \\
\hline $\begin{array}{l}\text { SS } \\
\text { STRFRM }\end{array}$ & $\begin{array}{l}\text { SOUNO SPEED SOUARED } \\
\text { A FRAC TION IZRRO TO ONE, INCLUSIVE) WHICH IS A MEASURE OF THE } \\
\text { COMPETENCE OF THE 2ONE. } \\
=0 \text {. WHEN ZONE IS SPALLED. } \\
=1 \text {. WHEN ZONE HAS NOT SPALLEO OR HAS COMPLETELY HEALED } \\
\text { AFTER SPALL. }\end{array}$ \\
\hline $\begin{array}{l}\text { S1 } \\
\text { SID } \\
\text { SIINT }\end{array}$ & $\begin{array}{l}\text { USEO TO MULTIPLY SHEAR MODULUS AND STRENGTH. } \\
\text { RAOIAL STRESS DEVIATOR } \\
\text { RADIAL STRAIN RATE } \\
\text { TEMPORARY STORAGE FOR RADIAL STRESS OEVIATCR SI, COMPUTEC JUST } \\
\text { BEFORE FAILURE CALC. MAY BE USEO AFTER FAILURE CALC. FOR } \\
\text { RECALCULATION OF OVER-RELAXED STRESS. }\end{array}$ \\
\hline $\begin{array}{l}\text { S2 } \\
\text { S2D } \\
\text { S2INT }\end{array}$ & $\begin{array}{l}\text { TANGENTIAL STRESS DEVIATCR } \\
\text { TANGENTIAL STRAIN RATE } \\
\text { TEMPORARY STORAGE FCR TANGENTIAL STRESS OEVIATOR S2, COMPUTED } \\
\text { JUST BEFORE FAILURE CALC. MAY BE USED AFTER FAILURE CALC. } \\
\text { FOR RECALCULATION OF CVER-RELAXEO STRESS. } \\
\text { THIRD STRESS DEVIAICR }\end{array}$ \\
\hline $\begin{array}{l}\text { TIME } \\
\text { TYYMMM } \\
\end{array}$ & 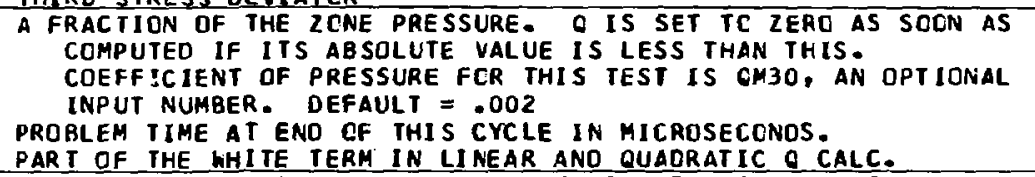 \\
\hline $\begin{array}{l}\text { VISI) } \\
\text { VEM(d) }\end{array}$ & $\begin{array}{l}\text { RELATIVE SPECIFIC VOLUME IRHCZERC/RHOI AT WHCLE CYCLE. } \\
\text { RELATIVE SPECIFIC VOLUHE AT WHICH STRENGTH OF MATERIAL IN THIS } \\
\text { ZONE GOES TO ZERC. USED TO DECIDE WHETHER ZONE IS SPALLED. } \\
\text { IF VOLUME OF } 20 N E \text { IS GREATER THAN VEM, ZCNE MUST GE SPALLED } \\
\text { ANO SPALL SENIINEL SKPEOS IS SET. NCTE - HYOROOYAMIC } \\
\text { MATERIAL IS NEVER ALLOWED IO SPALL. }\end{array}$ \\
\hline 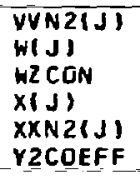 & 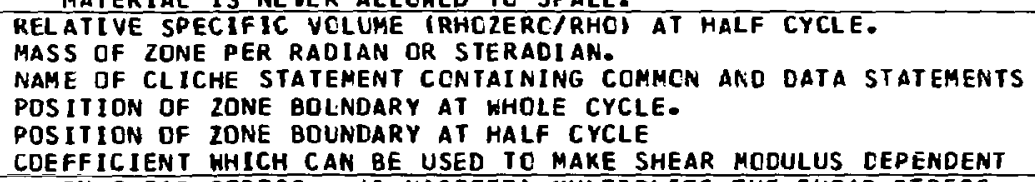 \\
\hline Y $2 F$ & 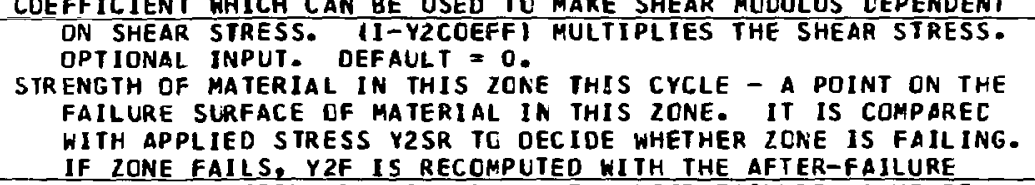 \\
\hline & $\begin{array}{l}\text { RUBBLE FRACTIDN AND COMPARED HITH AFTER-FAILURE VALUE OF } \\
\text { APPLIED STRESS Y2SRN TO DETERMINE WHETHER STRESSES WERE } \\
\text { OYER-RELAXED IN FAILURE. }\end{array}$ \\
\hline
\end{tabular}


Y2SR

APPLIED STRESS IN THIS ZONE THIS CYCLE - SQUARE RCNT DF 120. IT IS COMPAREO WITH STRENGTH YZF TO DECIOE WHETHER ZCNE IS FAILING.

APPL IED SIRESS IN THIS ZCINE AFTEA FAILURE HAS OCCURRED THIS CYCLE AND STRESSES HAVE BEEN RELAXED. IT IS COMPARED WITH AFTER-FAILURE STRENGTH TO DETERMINE WHETHER STRESSES WERE

Y 3 CR DVER-RELAXED IN FAILURE. CUBE ROOT OF I3D. AN INYARIANT FUNCTION CF STRESS DEVIATORS AND ONE DF THE CCORDINATE AXES GF THE FAILURE SPACE. 


\section{Acknowledgments}

The authors gratefully acknowledge the encouragement and support of W. H. McMaster. Special thanks are offered to P.H. Moulthrop, without whose support this project would not have been undertaken. We are deeply indebted to Mark Wilkins and John French, whose excellent computer program KO was the basis from which UKO was developed, and to John Schatz for reviewing the manuscript. 


\section{Appendix:}

\section{UKO Example Calculation (Pre-Schooner II)}

It should be noted that the one-dimensional (spherical) UKO calculations reported here can be compared to the experiment only with respect to the spall velocity at ground zero (GZ). After spallation begins, the field experiment becomes two dimensional.

$\mathrm{P}-\mu$ (pressure vs $\mu=(1-\mathrm{V}) / \mathrm{V}$, where $\mathrm{V}$ is relative specific volume) data are given in Fig. A-1. These data were obtained from the vitrophyre sam 2 ple 2 on page 2 of Ref. 12. This material is appropriate for use as an average medium for a depth of

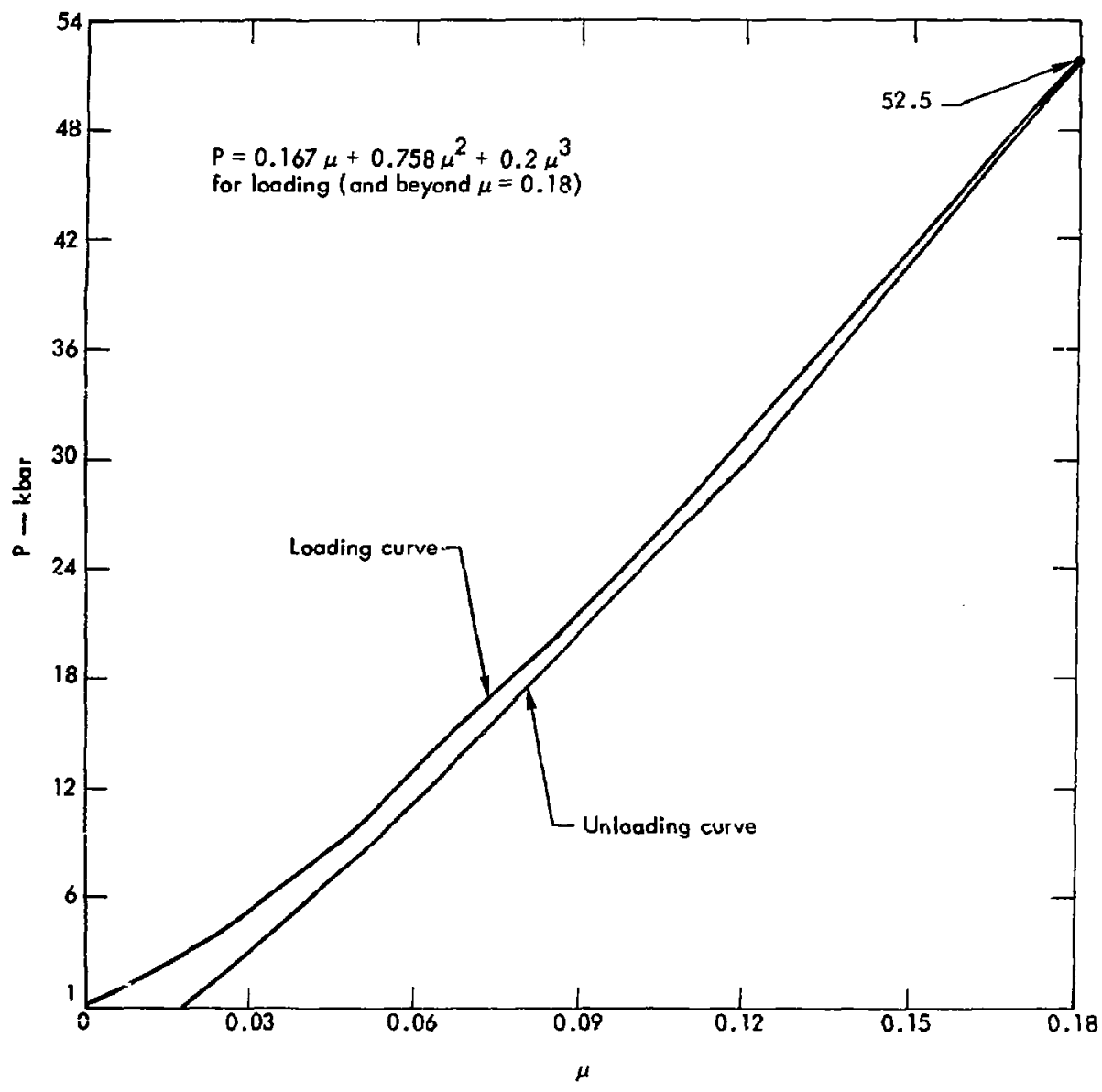

Fig. A-1. P vs $\mu$ for Pre-Schooner II. 
burial of $21.65 \mathrm{~m}$. We make no attempt to mock-up the many layers of geologic material at the site; these layers are described in Chapter 5 of Ref. 13, and from this source we also obtain the rernainder of the material properties of the rock. From Table 5.1 and Fig. 5.1 of Ref. 13, we obtain an average density of $2.33 \mathrm{~g} / \mathrm{cc}$, an average compressive strength of $5 \mathrm{kbar}$, and an average shear modulus of 0.2 Mbar. We arbitrarily set the failure surface as in Fig. A-2 by using the above compressive strength and

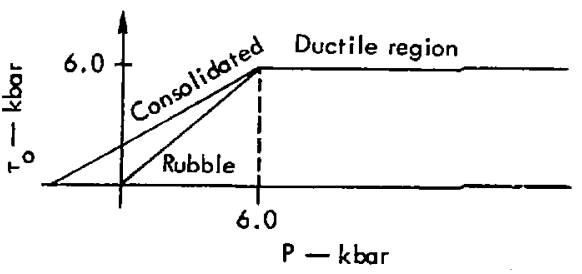

Fig. A-2. Failure surface for PreSchooner II. The same curves are used for extension and compression. by using the Schooner data ${ }^{14}$ as a guide, since the two types of rock are not too dissimilar. The region of the failure surface below a pressure of 6 kìar is most important, since only a small portion of the material experiences larger pressures, i.e., it is most important that the slope of the $\tau_{0}$ (octahedral shear stress) - $P$ curves be approximately correct.

The material is ductile above 6-kbar pressure and is brittle below $2 \mathrm{kbar}$, with a smooth linear transition between. For failure at negative pressure, the new surface is given by the rubble surface; and, for fallure above 6-kbar pressure, the failure surface is given by the consolidated surface. These two surfaces are mixed linearly between these two values.

The high-explosive (HE) used to create the crater was nitromethane (NM), which is a fluid and can be easily poured ir:to a preformed chamber. NM has a density of $1.13 \mathrm{~g} / \mathrm{cc}$ and an energy content of $1200 \mathrm{cal} / \mathrm{g}$. For the experiment, a spherical chamber had been prepared whose volume was to hold 100 tons of NM with its center at a depth of $21.6 \mathrm{~m}$. However, some of the explosive leaked, and the shot was fired with only $86 \%$ of the volume occupied. The acutal chamber volume was used in the UKO calculation, but the HE density was put at $0.97 \mathrm{~g} / \mathrm{cc}$. A standard KO (No. 1) EOS for HE was used, with its energy per unt mass inodified to the NM value. The HE chamber and emplacement description can be found in Ref. 15.

The camera used to record surface motion at $\mathrm{GZ}$ exposed slightly less than one frame per msec, and this low resolution was degraded further by the smoothing techniques necessary to perform the data analysis. Pictures were taken of a large ( $4 \times 16 \mathrm{ft}$ ) plywood target mounted on a heavy 6-in. o.d. pipe set in concrete, so the target was very inert and poorly coupled to the earth; these difficulties made it virtually impossible to resolve the acceleration details of the earth during the spall phase. However, if a state of dynamic equilibrium (plywood target and earth at the saine constant velocity) is reached and maintained sufficiently long, then the spall velocity should be measurable. From Fig. 4.2 of Ref. 15, the displacement-vs-time 
data from 30 to $70 \mathrm{msec}$ appear to fit this criterion quite well, so one obtains a spall velocity of $3.9 \mathrm{~cm} / \mathrm{msec}$ to within an accuracy of about $3 \%$.

Three calculations were run on UKO with various zone sizes so that the effect of artificial viscosity could be estimated and eliminated. The coarsely zoned problem had six zones in the HE $(\sim 46 \mathrm{~cm}$ each) and 45 zones in the rock $(\sim 3 \mathrm{~cm}$ each). The spall velocity of the outermost $43-\mathrm{cm}$ section was $3.12 \mathrm{~cm} / \mathrm{msec}$. Another problem was run in which each of the above zones was halved, and the outermost $43 \mathrm{~cm}$ of rock experienced a spall velocity of $3.52 \mathrm{~cm} / \mathrm{msec}$. Each zone was halved once more for the third calculation, and the outermost $43-\mathrm{cm}$ section spalled at a velocity of $3.76 \mathrm{~cm} / \mathrm{msec}$. These spall velocities can be plotted as a function of relative $z$ one size, and a curve can be extrapolated to zero zone size. The extrapolated spall velocity is approximately $4.0 \mathrm{~cm} / \mathrm{msec}$, compared with 3.9 from the experiment. The actual geologic materials are ruite inhomogeneous, the EOS's of the rock samples that were measured are quite crude, and the numerical model is quite simplistic. When these factors are considered, the agreement is considerably within that which would be considered satisfactory.

The $\mathrm{P}-\mathrm{V}$ data can be considered to be fairly reliable, even though the measurements are static. One might, however, expect the failure surfaces to change noticeably as the strain rates change. A similar calculational series was run (varying zone size) with the ductile strength raised by $50 \%$, and the resulting spall velocity was reduced by only $10 \%$.

Figures $A-3$ through $A-8$ show stress and velocity as a function of radius at various times, for the fine-zone calculation of Pre-Schooner II. The first two of these figures show the system when the shock is approaching the free surface. Note that the pressure is not continuous across the HE-rock interface, because of the presence of shear modulus in the rock. The rarefaction is accompanied by spallation in Figs. A-7 and $A-8$. Figure $A-8$ specifically shows the velocity increase at the rarefaction front.

After the rarefaction has reached the cavity, the $\mathrm{HE}$ gas begins to recompact the spalled material; and the spalled material and the gas-acceleration phase begins, in which a second push of the material is accomplished. The actual recompaction process is quite two dimensional and is included here only to demonstrate code behavior for a portion of the rock mechanics model that is quite difficult to handle. Note that the recompaction process involves a discontinuity in the material behavior, i.e., material at zero pressure (no matter what density) is suddenly changed to a material for which the EOS must be used. A large linear $q$ is used to damp out noises at the recompaction front (see Fig. A-7), although some noise remains. In Fig. A-7 we also observe a materlal quasi-interface that results from the fact that the rock to the right of the quasiinterface has lost its elastic properties as a result of the spallation process, and the pressure has not become large enough to heal the material. This last feature of the calculation is a result of the specific way in which the UKO model allows spalled material to heal. Even thrugh this part of the model is considered experimental, examination of Fig. A-8 shows that the solution is well behaved. It should be added 


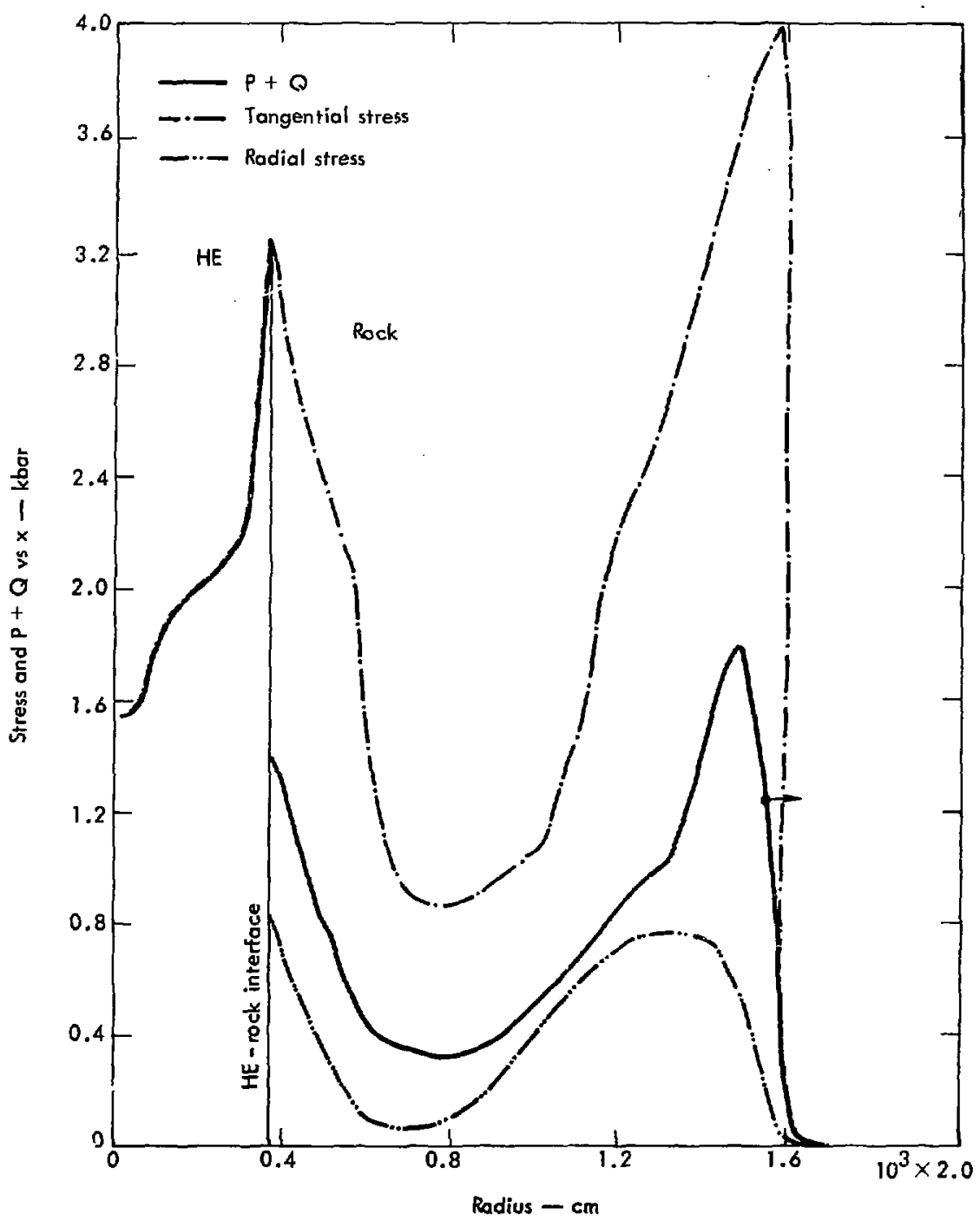

Fig. A-3. Stress profiles for the diverging wave. Time $=3.0 \mathrm{msec}$ at Cycle 507 .

that the energy conservation is excellent; the energy content of the problem changes by less than $0.01 \%$ when the problem goes from cycle 507 to cycle 1683 (Figs. A-3 to A-8). 


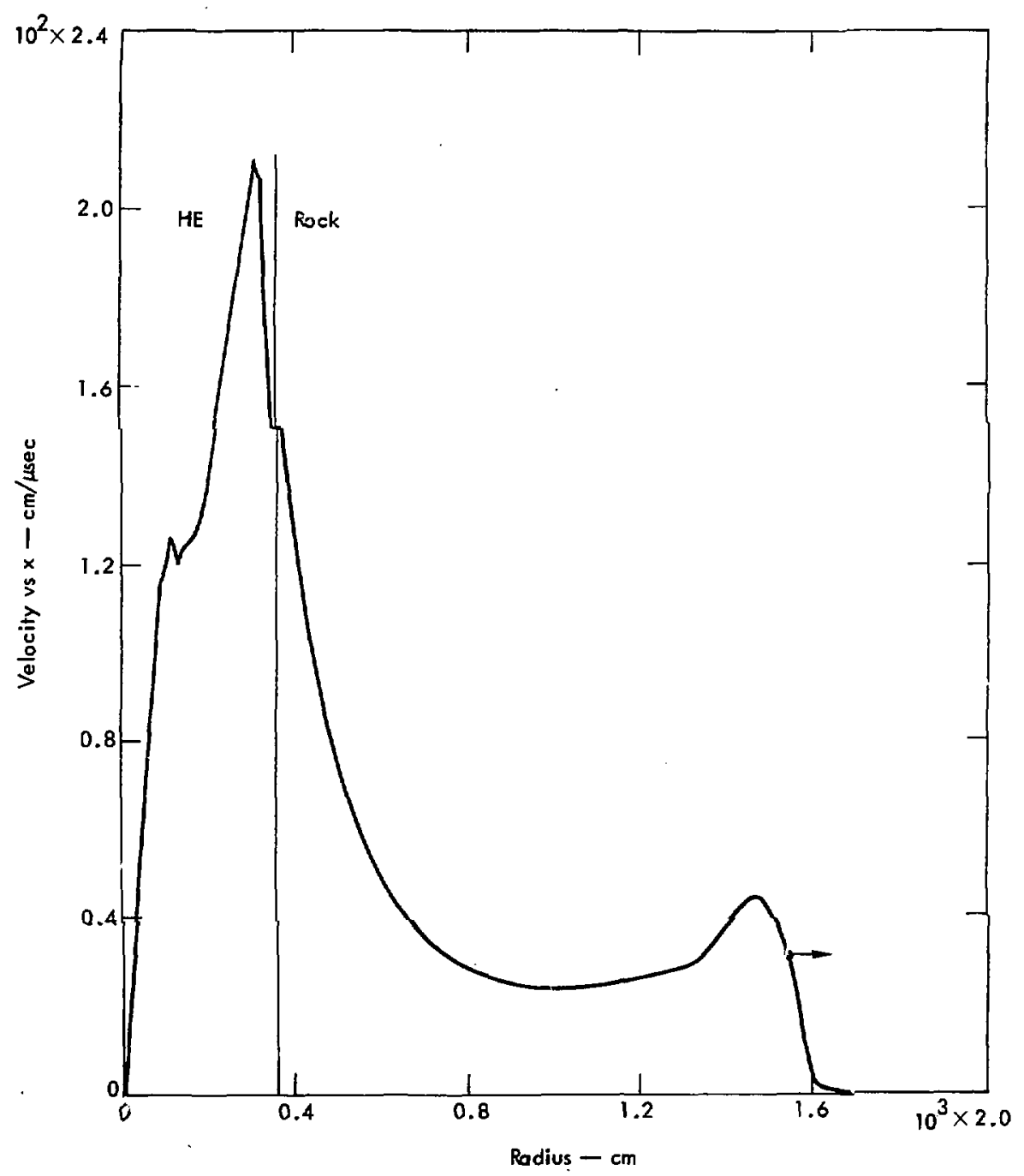

Fig. A-4. Velocity profiles for the diverging wave. Time $=3.0 \mathrm{msec}$ at Cycle 507 . 


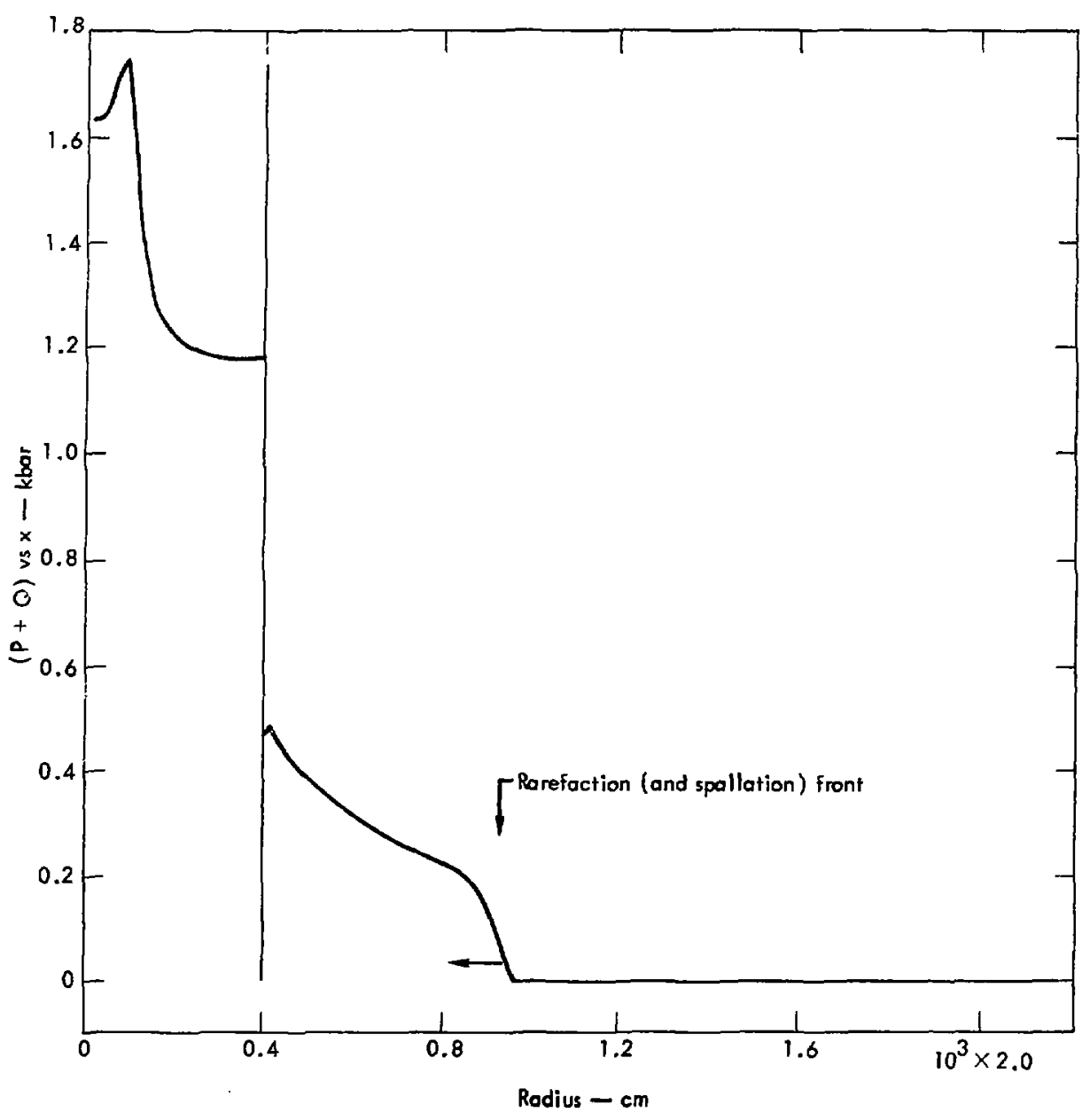

Fig. A-5. Stress profile for the rarefaction wave. Time $=7.0 \mathrm{msec}$ at Cycle 922 . 


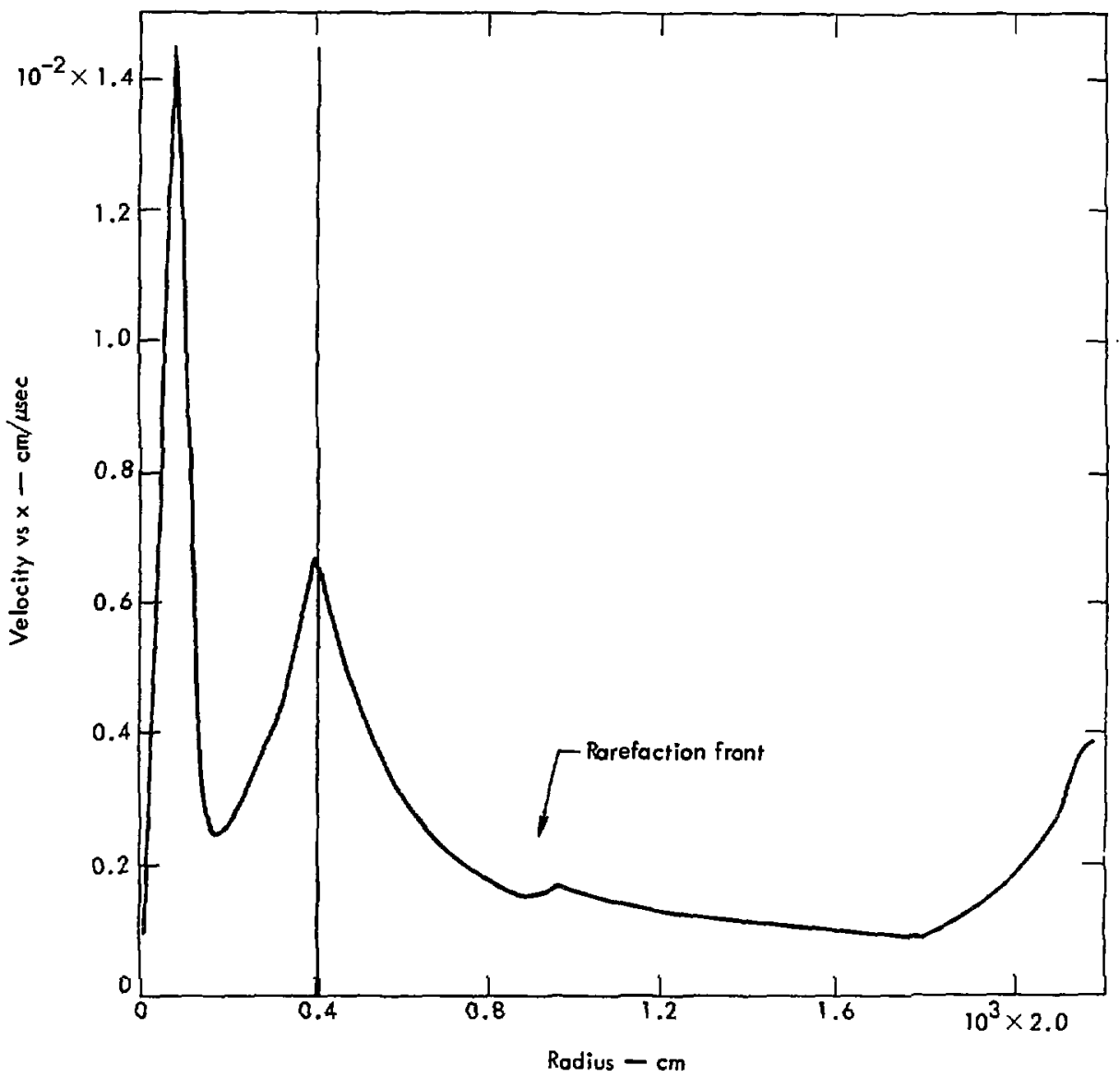

Fig. A-6. Velocity profile for the rarefaction wave. Time $=7.0 \mathrm{msec}$ at Cycle 922 . 


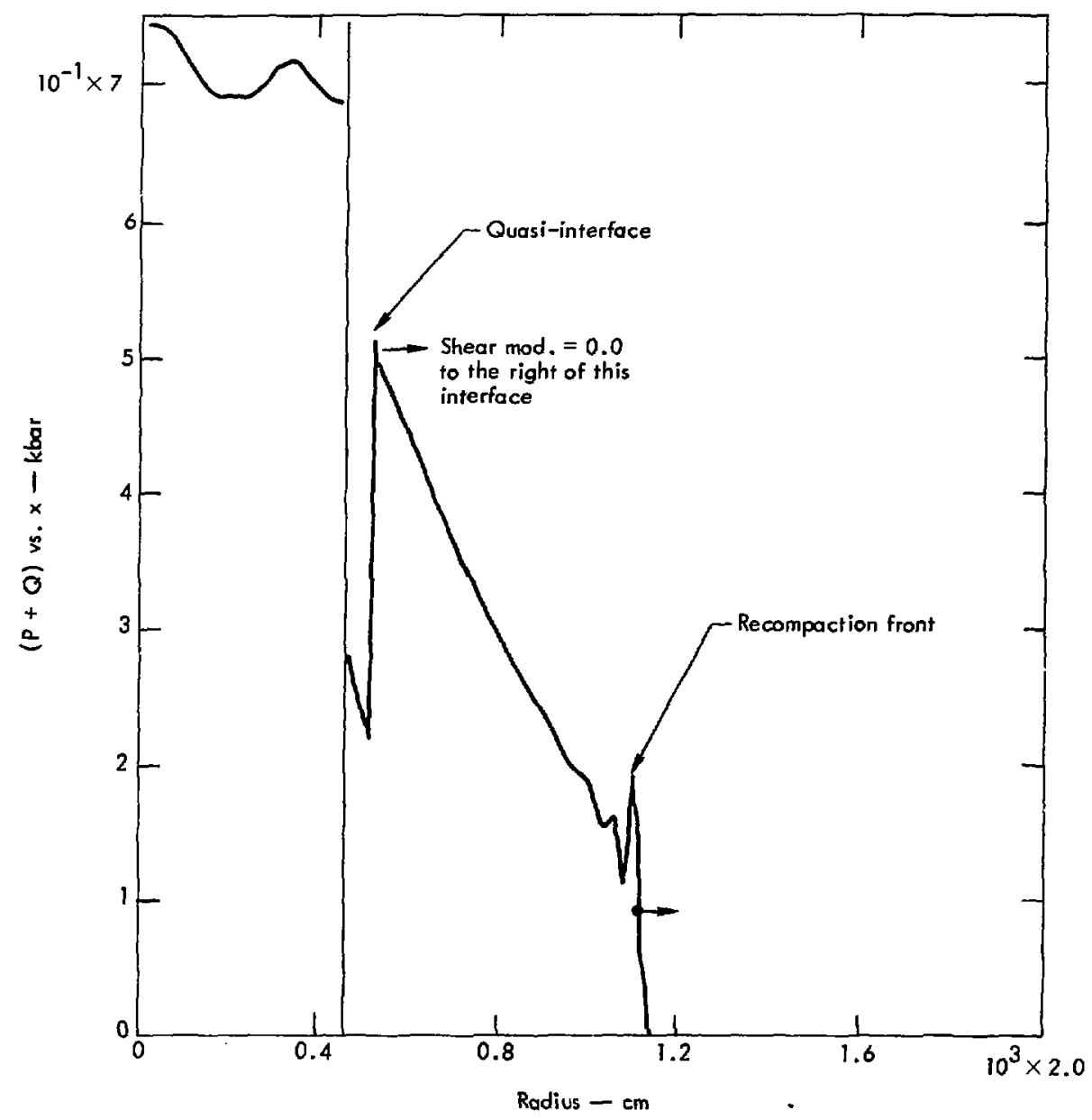

Fig. A-7. Strese profile for the recompaction wave. Time $=13.0 \mathrm{msec}$ at Cycle 1683 . 


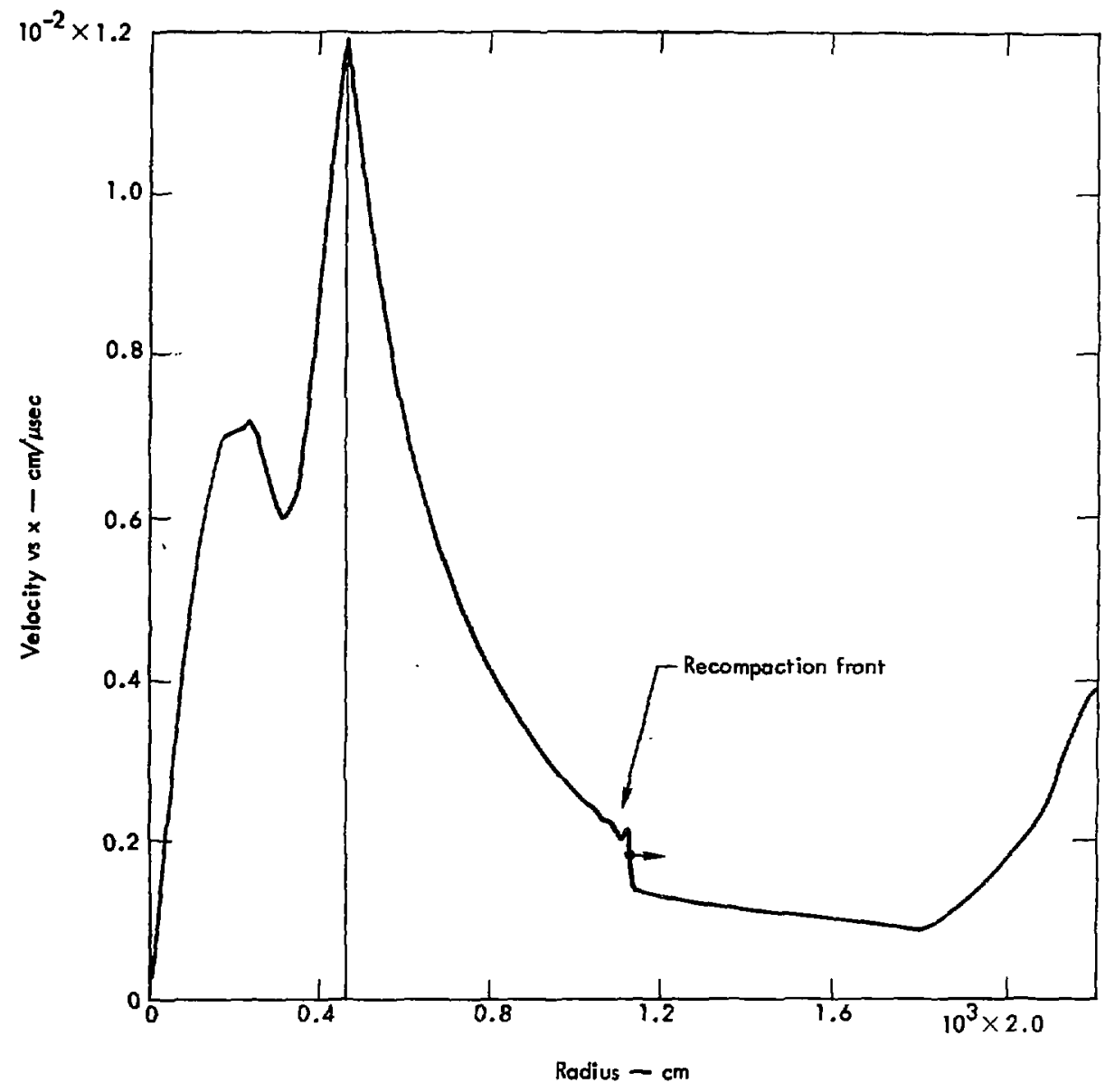

Fig. A-8. Velocity profile for the recompaction wave. Time $=13.0 \mathrm{msec}$ at Cycle 1683 . 


\section{References}

1. M. L. Wilkins, Calculation of Elastic Plastic Flow, Lawrence Livermore Laboratory, Rept. UCRL-7322, Rev. 1 (1969).

2. A. Nadai, Theory of Flow and Fracture of Solids (McGraw-Hill, New York, 1950), p. 92 .

3. J. C. Jaeger, Elasticity, Fracture and Flow with Engineering and Geological Application (Methuen and Co. Ltd., London, 1969), 3rd ed,

4. H. Liebowitz, Fracture, an Advanced Treatise (Academic, New York, 1968), Vol. 2, p. 329 .

5. J. C. Jaeger and N. G. W. Cook, Fundamentals of Rock Mechanics (Methuen and Co. Ltd., London, 1969), pp. 9-52.

6. J. W. White, An Invariant Description of Failure for an Isotropic Medium, Lawrence Livermore Laboratory, Rept. UCRL-72065, Rev. 2 (1972).

7. M. L. Wilkins, Calculation of Elastic-Viscous-Plastic Effects in Materials, Lawrence Livermore Laboratory, Rept. UCRL-72639 (1970).

8. J. Von Neumann and R. D. Richtmyer, "A Method for the Numerical Calculation of Hydrodynamics Shocks," J. Appl. Phys, 21, 232 (1950).

9. J. W. White, A New Form of Artificial Viscosity, Lawrence Livermore Laboratory, Rept. UCRL-73861, Rev. 1 (1972).

10. J. W. White, A New Form of Artificial Viscosity: Postscript, Lawrence Livermore Laboratory, Rept. UCRL-73861, Rev. 1, Aduendum, Rev. 1 (1972).

11. R. D. Richtmyer and K. W. Morton, Difference Methods for Initial Value Problems (Wiley Interscience, New York, 1967), 2nd ed.

12. H. Heard, Lawrence Livermore Laboratory, personal communication (October 1965).

13. R. J. Lutton, F, E. Girucky, R. W. Hunt, and J. R. Curro, Jr., Project PreSchooner II: Preshot Geolagic and Engineering Properties Investigations, PNE-509 (December 1967).

14. H. Heard, Lawrence Livermore Laboratory, personal communication (December 1968).

15. B. C. Hughes, Project Pre-Schooner II: Technical Director's Summary Report, PNE-507 (October 1966 \}. 